\title{
Relationship between COVID-19 infection rates and air pollution, geo-meteorological, and social parameters
}

\author{
Md. Shareful Hassan (1D - Mohammad Amir Hossain \\ Bhuiyan • Faysal Tareq $\cdot$ Md. Bodrud-Doza $•$ Saikat \\ Mandal Tanu $\cdot$ Khondkar Ayaz Rabbani
}

Received: 12 June 2020 / Accepted: 16 December 2020 / Published online: 4 January 2021

(C) The Author(s), under exclusive licence to Springer Nature Switzerland AG part of Springer Nature 2021

\begin{abstract}
Like all infectious diseases, the infection rate of COVID-19 is dependent on many variables. In order to effectively prepare a localized plan for infectious disease management, it is important to find the relationship between COVID-19 infection rate and other key variables. This study aims to understand the spatial relationships between COVID-19 infection rate and key variables of air pollution, geo-meteorological, and social parameters in Dhaka, Bangladesh. The relationship was analyzed using Geographically Weighted Regression (GWR) model and Geographic Information System (GIS) by means of COVID-19 infection rate as a dependent variable and 17 independent variables. This study revealed that air pollution parameters like $\mathrm{PM}_{2.5}$
\end{abstract}

M. S. Hassan $(\bowtie) \cdot$ M. A. H. Bhuiyan

Department of Environmental Sciences, Jahangirnagar University, Dhaka 1342, Bangladesh

e-mail: shareful@gmx.com

F. Tareq

Institute of Energy, University of Dhaka, Dhaka 1000, Bangladesh

M. Bodrud-Doza

Climate Change Programme, BRAC Bangladesh, Dhaka,

Bangladesh

S. M. Tanu

Department of Geography and Environment, Jahangirnagar

University, Dhaka 1342, Bangladesh

K. A. Rabbani

Department of Environmental Science and Management, Independent University Bangladesh (IUB), Dhaka, Bangladesh $(p<0.02)$, AOT $(p<0.01), \mathrm{CO}(p<0.05)$, water vapor $(p<0.01)$, and $\mathrm{O}_{3}(p<0.01)$ were highly correlated with COVID-19 infection rate while geo-meteorological parameters like DEM $(p<0.01)$, wind pressure $(p<0.01)$, LST $(p<0.04)$, rainfall $(p<0.01)$, and wind speed $(p<0.03)$ were also similarly associated. Social parameters like population density $(p<0.01)$, brickfield density $(p<0.02)$, and poverty level $(p<0.01)$ showed high coefficients as the key independent variables to COVID19 infection rate. Significant robust relationships between these factors were found in the middle and southern parts of the city where the reported COVID-19 infection case was also higher. Relevant agencies can utilize these findings to formulate new and smart strategies for reducing infectious diseases like COVID-19 in Dhaka and in similar urban cities around the world. Future studies will have more variables including ecological, meteorological, and economical to model and understand the spread of COVID-19.

Keywords COVID-19 · Dhaka city · Bangladesh · GIS · Geographically Weighted Regression (GWR)

\section{Introduction}

In December 2019, the first reported cases of a new infectious disease were found in Wuhan, China (Guan et al. 2020). It was named COVID-19, a new virus of the group of coronavirus, which is also known as severe acute respiratory Syndrome Coronavirus 2 (SARS- 
CoV-2) (Gorbalenya et al. 2020; Pedrosa 2020). The typical clinical symptoms include fever, dry cough, myalgia, and pneumonia which may cause progressive respiratory failure due to alveolar damage and may eventually lead to death (Huang et al. 2020). On 11 March 2020, the World Health Organization (WHO) has declared the COVID-19 as a public health emergency because the number of cases drastically increased outside of China (WHO 2020). As of May 20, 2020, $4,900,255$ confirmed cases in over 200 countries/ regions and 323,341 deaths were reported worldwide (University 2020).

Like other countries, Bangladesh is also suffering from this global pandemic. The country has a population of more than 163.7 million with a population density of $1265 / \mathrm{km}^{2}$ making it one of the most densely populated countries in the world (Worldometers 2017). Almost $37.4 \%$ of its total population lives in urban areas with a high level of air pollution ("Bangladesh-Urban population” 2020). Most Bangladeshi urban areas, specially its capital Dhaka, are highly exposed to different types of air pollutants, e.g., $\mathrm{PM}_{2.5}, \mathrm{PM}_{10}, \mathrm{COx}, \mathrm{NOx}, \mathrm{SOx}$, and dust because of uncontrolled urbanization, industrial emissions, high traffic density, and construction activities. Because of high population density and high pollution levels have an adverse effect on public health, the residents of Dhaka are highly susceptible to the risk of COVID-19 infection. As of May 22, 2020, according to the Institute of Epidemiology, Disease Control and Research (IEDCR), Bangladesh, reported 28,521 confirmed cases with total death of 408 in the whole country. The majority of the confirmed cases were identified in Dhaka which is also the epicenter of this infectious disease, and till now, there have been 12,386 confirmed cases reported with 103 deaths ("Bangladesh Covid-19 Update (2020)" 2020).

Research investigating the relationships between COVID-19 infection rate and air pollution is starting to appear in the literature (Bontempi 2020a; He et al. 2020). A regional study in 4 countries of Europe to examine the relationship between $\mathrm{NO}_{2}$ and the number of fatalities due to COVID-19 showed that long-term exposure to $\mathrm{NO}_{2}$ may be one of the most important contributors to fatality caused by the virus (Ogen 2020). Researchers in Italy have speculated that atmospheric pollution is a co-factor in inducing high levels of deaths due to COVID-19 (Conticini et al. 2020; Martelletti and Martelletti 2020). A nationwide crosssectional study in the USA considering 20 confounding factors including population density, weather, and socioeconomic variables showed that $\mathrm{PM}_{2.5}$ had a clear link to COVID-19 mortality rates (Wu et al. 2020a). Conticini et al. (2020) have suggested considering population, social habits, and meteorological condition together with air pollution when analyzing COVID-19 spread and mortality rates. Moreover, Arabrahmatipour et al. (2020) conclude that COVID-19 impacts not only the public health but also the mental health. However, caution is recommended by Bontempi (2020a) who has shown that there is no strong evidence that COVID-19 diffusion mechanism occurs through the air using $\mathrm{PM}_{10}$ as a carrier even though $\mathrm{PM}_{10}$ was shown to have a linear functional relationship with cardiovascular disease and non-accidental mortality rate in Spain (Ortiz et al. 2017). A cross-sectional study was carried out to evaluate the impact of indoor air pollution related to the respiratory health system where a strong positive association was found between the concentration of $\mathrm{PM}_{2.5}$ and increased maternal lung symptoms, which is susceptible to COVID-19 (Mulenga and Siziya 2019). An 11 city study was conducted in China where non-linear models were employed to investigate the relationship between non-accidental mortality and $\mathrm{NO}_{2}, \mathrm{PM}_{2.5}$, temperature, and relative humidity as covariates (He et al. 2020). The researchers found higher effect estimates of intermediate-term $\mathrm{NO}_{2}$ exposure on respiratory mortality compared to that of the short term but the differences were too small to be considered statistically significant. Bontempi (2020b) also mentioned that the airborne diffusion of COVID-19 is affected by the local air particulate matter (PM) in northern Italy but finds that there is no significant relationship between $\mathrm{PM}_{10}$ and COVID-19 mortality rates.

There have also been studies relating to COVID-19 infection rates and geo-meteorological parameters. Temperature, humidity, and rainfall may have a direct influence on spreading the COVID-19 and other infectious vector-borne diseases (Casanova et al. 2010; Qi et al. 2020). Xie and Zhu (2020a) conducted a study in 122 cities across China to establish epidemiological and experimental research on ambient temperature and COVID-19 infection. Humidity, wind speed, and temperature are inversely associated with the infection rate of the COVID-19 in 310 areas from 116 countries. Islam et al. (2020) conducted this research and found that both cold and dry environments were favorable to the spread of COVID-19. Xie and Zhu (2020b) found a negative linear relationship between the COVID-19 confirmed 
cases and mean temperature in 122 cities in mainland China, suggesting warmer weather will not be a crucial factor to reduce the infection case of COVID-19. On the contrary, higher mean temperature and average relative humidity are quite significant in enhancing the COVID19 contamination rate in Brazil (Auler et al. 2020), although average temperature and relative humidity were not consistent in terms of geographical areas, because of spatial heterogeneity problems (Qi et al. 2020). Bashir et al. (2020) found a positive relationship between the COVID-19 and average temperature, minimum temperature, and air quality in New York, USA, although they found a negative relationship with rainfall. Hu et al. (2013) assumed that the transmissibility of an infectious disease is totally dependent on the population density of an area. They found that lower population density has the lower reported cases of an infectious disease than the higher density locations. There are other results revealed and concluded that population density is one of the key factors to control the COVID-19 (Luo et al. 2020; Pedrosa 2020; Sajadi et al. 1992). Also, integration of environmental, climatic, bioindication approaches of air pollution, and manmade factors are useful for analyzing and predicting vector-borne and infectious diseases (Benaissa and Alkama 2019; Ceccato et al. 2018).

Many of the literature reviewed suggested reduction of air pollution as a strategy to minimize the adverse health effects of COVID-19. Conclusions were based on a limited number of particular air pollution and geo-meteorological variables. Like any public health issue, there are many more factors that need to be considered for a better understanding of effective management strategies to control COVID19 , specially in a city like Dhaka where the COVID-19 infection rates show variation in different parts of the city even though high levels of air pollution are equally prevalent all across the city. This study will fill this knowledge gap identified by examining the relationship between COVID-19 infection rate and 17 other parameters including air pollution, geo-metrological, and social parameters. This study is unique in that it looks not only at air pollution but other linked factors in Dhaka, one of the most densely populated and polluted cities in the world. To the best of our knowledge, this is the first time that all these variables have been modeled using standard advanced statistical and GIS modeling to understand the relationship with COVID-19 infection rates in Dhaka.
This study starts with an introduction, a literature review on the topic, and presentation of the hypothesis while the "Materials and methods" section describes the methodology of the study which includes a concise outline of the parameters studied here that influence the COVID-19 infection rate, the method used for collection of sample data, and model specifications. The "Results" section outlines the results of the descriptive analysis and an interpretation of the spatial relationships between COVID-19 infection rates and air pollution, geo-meteorological, and social parameters by using Geographically Weighted Regression (GWR). The "Discussion" section elucidates the key findings and compares the results of this study with similar studies in the literature, and the final section summarizes the main points revealed in this study.

\section{Materials and methods}

The overall research framework is summarized in Fig. 2 and is described in detail below.

\section{Study location}

The study area is located in Dhaka (or Dhaka Metropolitan Area) which is the administrative and financial capital of Bangladesh (Fig. 1). It has an area of $370 \mathrm{~km}^{2}$ with around 20.28 million inhabitants and geographically lies between $23^{\circ} 40^{\prime}$ and $23^{\circ} 54^{\prime} \mathrm{N}$ latitude and $90^{\circ} 20^{\prime}$ and $90^{\circ} 28^{\prime} \mathrm{E}$ longitude (Ahmed et al. 2013; Hoque et al. 2007). Geographically, Dhaka city is located in the lower reaches of the Ganges Delta on the tributary of the Meghna Ganges river system (Ahmed et al. 2014). The monthly average temperature ranges from 25 to $31^{\circ} \mathrm{C}$; the mean relative humidity and evaporation range between 80 and $90 \%$ and 80 and $130 \mathrm{~mm}$, respectively (BMD 2020). The topography of the city is relatively flat and its elevation varies between 0.5 and $12 \mathrm{~m}$ (Hoque et al. 2007) (Fig. 2).

\section{COVID-19 data}

Daily Thana (small administrative unit of Bangladesh) wise COVID-19 infection rate was used from two government sources in this study (Table 1). This database was entered into a city GIS shapefile for further statistical and spatial analyses. Death statistics of COVID-19 data was not possible to collect because these are not yet 

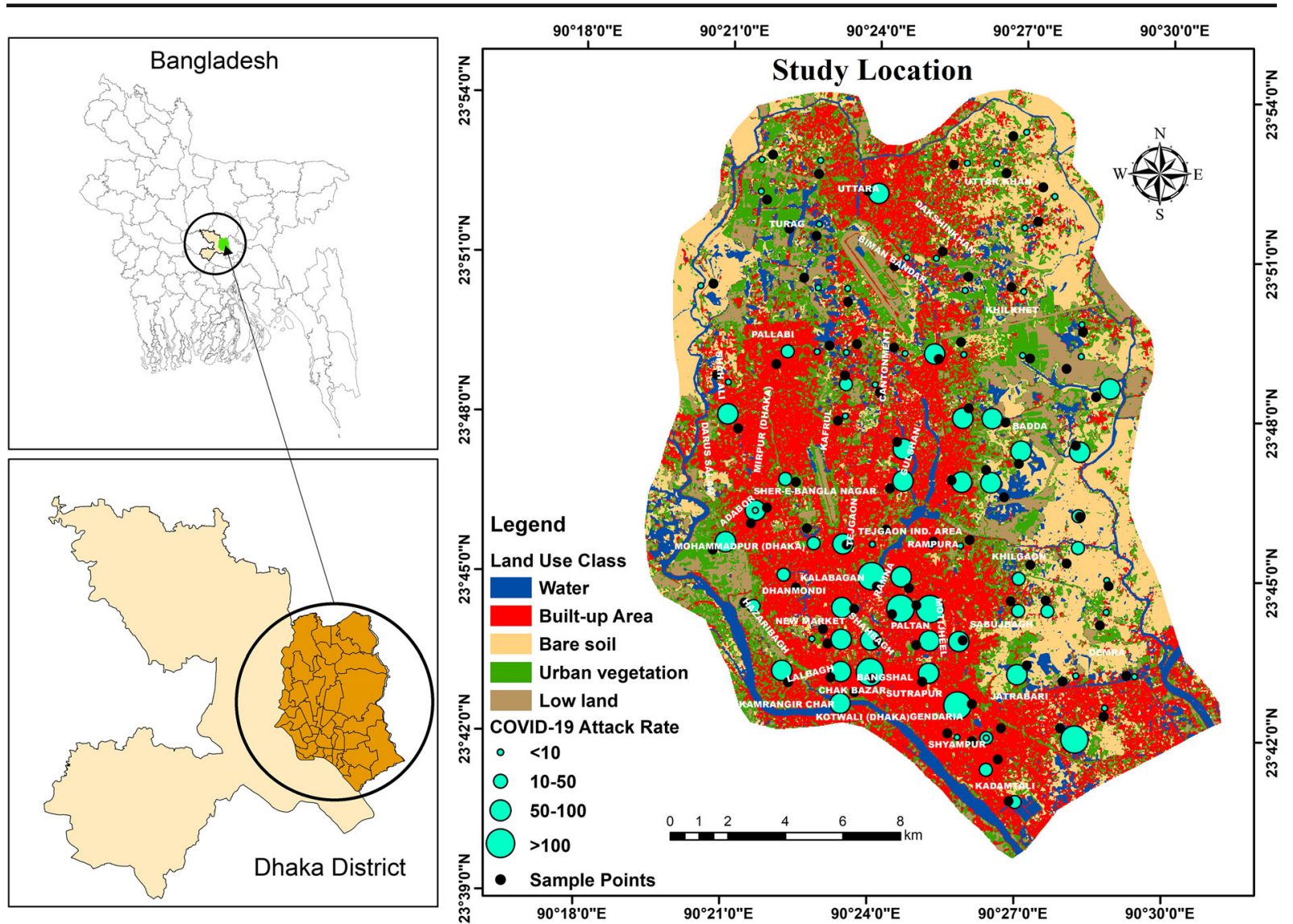

Fig. 1 The geographical location and distribution of COVID-19 infection in Dhaka city. Cyan circles show the ratio of infection rate on the land use map. The small black dots are the sample points for data collection

publicly available at the time of writing this paper (May 23, 2020).

\section{Collection of sample points}

Eighty-six points from different parts of Dhaka were randomly chosen from the study area (Fig. 1). On-screen digitization process was used to extract these points from different locations of the study area with the help of high-resolution Google map and a combination of other relevant secondary data.

\section{Air pollution parameters}

Seven air pollution parameters, namely, particulate matter $\left(\mathrm{PM}_{2.5}\right)$, nitrogen dioxide $\left(\mathrm{NO}_{2}\right)$, aerosol optical thickness (AOT), sulfur dioxide $\left(\mathrm{SO}_{2}\right)$, carbon monoxide $(\mathrm{CO})$, water vapor, and ozone $\left(\mathrm{O}_{3}\right)$ of the period 2010-2020 (May), were used in this study (Table 1). Brickfield density data was also included in the regression model because this is considered as one of the main sources of air pollution in Dhaka (Guttikunda et al. 2013). The annual average of high-resolution atmospheric data from different satellites was analyzed to derive spatial maps of each parameter because satellite-based air quality mapping and monitoring in urban areas have been advent as a new avenue of atmospheric research (Engel-Cox et al. 2004). After pre- and post-processing all of the temporal air pollution parameters, the digital number of each parameter was extracted for 86 sample points. Finally, 7 different maps of the annual average concentration of each parameter were generated using a point interpolation method of spatial analysis technique.

\section{Geo-meteorological parameters}

The raster data of the digital elevation model or DEM $(\mathrm{m})$, wind pressure $\left(\mathrm{ms}^{-1}\right)$, rainfall $(\mathrm{mm})$, land surface temperature or LST $\left({ }^{\circ} \mathrm{C}\right)$, and wind speed (mph) were 


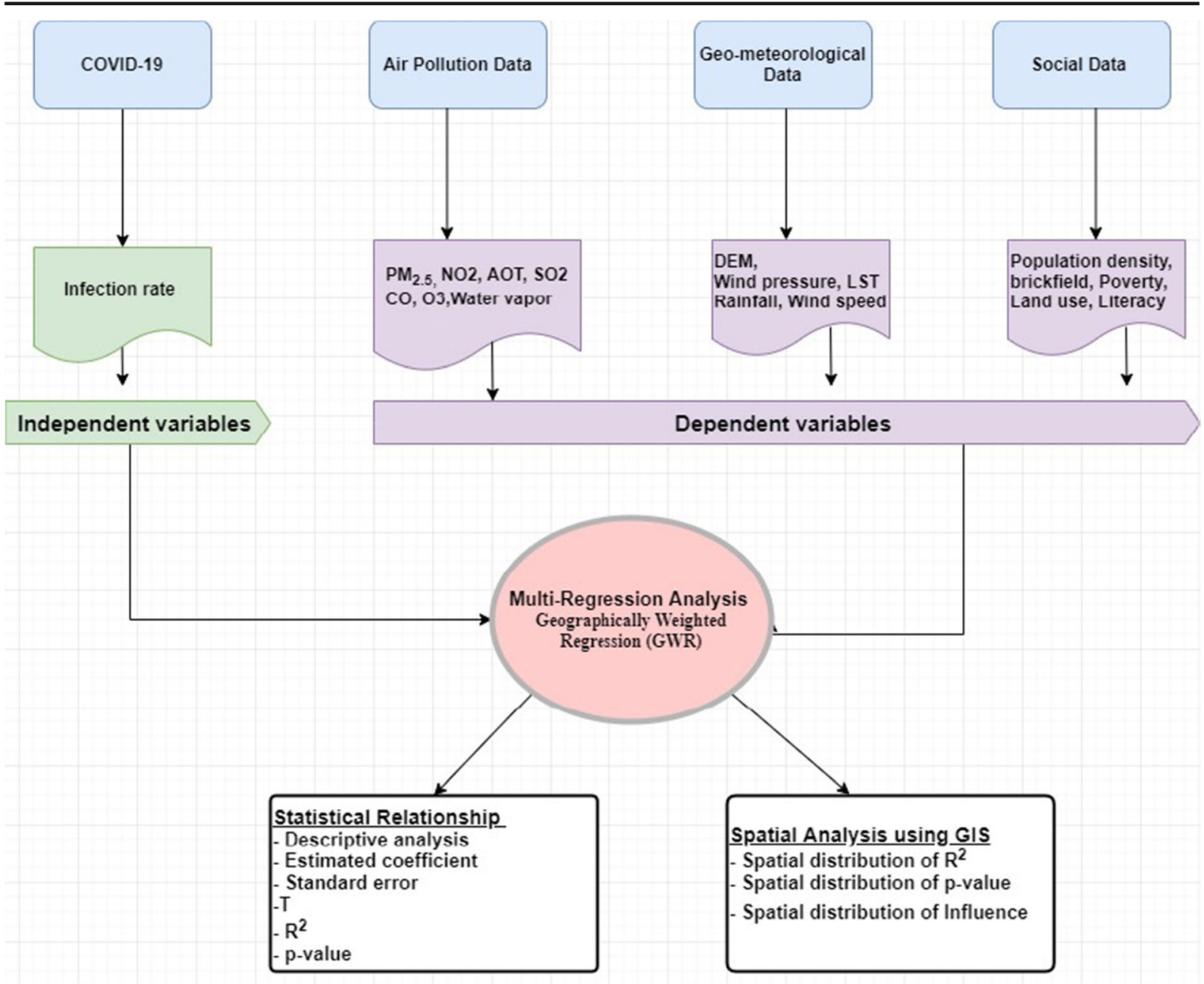

Fig. 2 The flowchart of the research methodology

collected from different sources and satellite data (Table 1). These geo-rectified data were analyzed using GIS platform and finally resampled into $30-\mathrm{m}$ resolution in order to make an alignment with land use resolution. Finally, 4 different maps of the annual average concentration of each parameter were generated using spatial analysis technique, while the DEM had only 1 -year data.

\section{Social parameters}

Both vector and raster databases were used to classify the social variables (Table 1). All the vector data, after converting into raster datasets, rasterized to $30-\mathrm{m}$ resolution keeping GCS-WGS-1984 and D-WGS-1984 geographic coordinate system and datum, respectively. Poverty, population density, and literacy are included as a social parameter as these are considered as important variables to understand the relationship with COVID-19 infection rates (Luo et al. 2020; Sajadi et al. 1992).

Geographically Weighted Regression

Geographically Weighted Regression (GWR) method was used to map the association between ambient air pollution, geo-meteorological, and social data with the COVID-19 infection rate. Geographically Weighted Regression (GWR) is an approach of exploring spatial nonstationary which permits different relationships to exist at different points in space by the process of calibrating several regression models in a systematic process (Leung et al. 2000). The fundamental principle of GWR is that parameters may be estimated anywhere in 
Table 1 Characteristics of different databases used in the study

\begin{tabular}{|c|c|c|c|c|}
\hline Theme & Parameters (independent) & Unit & Data sources & $\begin{array}{l}\text { Temporal/data } \\
\text { year }\end{array}$ \\
\hline \multirow[t]{7}{*}{ Air pollutants } & $\mathrm{PM}_{2.5}$ & $\mu \mathrm{g} / \mathrm{m}^{3}$ & $\begin{array}{l}\text { https://sedac.ciesin.columbia.edu/ } \\
\text { https://www.ecmwf. } \\
\text { int/en/forecasts/accessing-forecasts }\end{array}$ & 2010-2020 (April) \\
\hline & $\mathrm{NO}_{2}$ & $\mathrm{~nm}^{2}$ & https://aura.gsfc.nasa.gov/ & 2010-2020 (April) \\
\hline & AOT & & https://neo.sci.gsfc.nasa.gov/ & 2010-2020 (April) \\
\hline & $\mathrm{SO}_{2}$ & Ppm & https://search.earthdata.nasa.gov/search & 2019-2020 (April) \\
\hline & $\mathrm{CO}$ & Ppm & https://search.earthdata.nasa.gov/search & 2010-2020 (April) \\
\hline & Water vapor & $\mathrm{Cm}$ & https://www.worldclim.org/data/worldclim21.html & 2010-2020 (April) \\
\hline & $\mathrm{O}_{3}$ & Ppm & https://search.earthdata.nasa.gov/search & 2010-2020 (April) \\
\hline \multirow[t]{5}{*}{ Geo-meteorological } & DEM & Meter & https://search.earthdata.nasa.gov/search & 2019 \\
\hline & Wind pressure & $\mathrm{m} \mathrm{s}^{-1}$ & https://www.worldclim.org/data/worldclim21.html & 2010-2020 (April) \\
\hline & LST & ${ }^{\circ} \mathrm{C}$ & https://search.earthdata.nasa.gov/search & 2010-2020 (April) \\
\hline & Rainfall & $\mathrm{Mm}$ & https://gpm.nasa.gov/trmm & 2010-2020 (April) \\
\hline & Wind speed & $\mathrm{Mph}$ & https://www.worldclim.org/data/worldclim21.html & 2017 \\
\hline \multirow[t]{5}{*}{ Social } & Population density & Per dot & Bangladesh Bureau of Statistics & 2011 \\
\hline & Brickfield & Meter & Direct digitization & 2019 \\
\hline & Poverty & $\%$ & https://data.humdata.org/ & 2017 \\
\hline & Land use & Class & Landsat 8 & 2019 \\
\hline & Literacy & $\%$ & Bangladesh Bureau of Statistics & 2011 \\
\hline Dependent variable & $\begin{array}{l}\text { COVID-19 } \\
\text { infection/mortality }\end{array}$ & $\begin{array}{l}\text { Upazila } \\
\text { Wise }\end{array}$ & $\begin{array}{l}\text { Bangladesh Ministry of Health } \\
\text { https://www.iedcr.gov.bd/ }\end{array}$ & 2020 (May) \\
\hline
\end{tabular}

the study area given a dependent variable and a set of one or more independent variables that have been measured at places whose location is known (Charlton and Fotheringham 2014; Fotheringham et al. 1998). GWR offers the potential of investigating relationships that vary over space between variables in a regression model and it is quite a handy approach that allows complex spatial variations in parameter estimates to be identified, mapped, and modeled (Brunsdon et al. 1996; Wheeler and Páez 2010).

In the GWR model component, $X$ is a matrix containing a set of independent or predictor variables and $Y$ is a vector of dependent or response variables. The main calculation of this model is in Eq. 1.

$$
Y=\beta_{\mathrm{o}}+\beta_{1} X_{1}+\beta_{2} X_{2}+\ldots \ldots \beta_{n} X_{n}+\varepsilon
$$

where $Y$ is the dependent variable, $0_{0} \ldots \beta_{n}$. are regression coefficients, $X_{1 \ldots} X_{n}$ is the independent variables, and $\varepsilon$ is the residuals error. In this study, Geographically Weighted Regression model was used for air pollution, geo-meteorological, and social parameters individually and each run was done in triplicate. These main GWR calculations for the models are given below.

For air pollution parameters:

$$
\begin{aligned}
\operatorname{COVID}-19(Y)= & \beta_{o}+\beta_{1}\left(\mathrm{PM}_{2.5}\right)+\beta_{2}\left(\mathrm{NO}_{2}\right) \\
& +\beta_{3}(\mathrm{AOT})+\beta_{4}\left(\mathrm{SO}_{2}\right) \\
& +\beta_{5}(\mathrm{CO})+\beta_{6}(\mathrm{WV}) \\
& +\beta_{7}\left(\mathrm{O}_{3}\right)+\varepsilon
\end{aligned}
$$

For geo-meteorological parameters:

$$
\begin{aligned}
\text { COVID-19 }= & \beta_{\mathrm{o}}+\beta_{1}(\mathrm{DEM})+\beta_{2}(\mathrm{WP}) \\
& +\beta_{3}(\mathrm{LST})+\beta_{4}(\text { Rainfall }) \\
& +\beta_{5}(\text { Wind speed })+\varepsilon
\end{aligned}
$$


For social parameters:

$$
\begin{aligned}
\operatorname{COVID}-19(Y)= & \beta_{\mathrm{o}}+\beta_{1}(\text { Pop density }) \\
& +\beta_{2}(\text { Brickfield }) \\
& +\beta_{3}(\text { Poverty })+\beta_{4}(\text { Land use }) \\
& +\beta_{5}(\text { Literacy })+\varepsilon
\end{aligned}
$$

After executing these 3 models, the resultant databases were exported, and the coefficient, standard error, $T, p$ value, and $r^{2}$ were input into ArcGIS software for deriving some spatial maps using a point interpolation method.

Point interpolation using Inverse Weighted Distance

Inverse Weighted Distance (IWD) method was used for point data interpolation because this multivariate method is very useful for temporal climate and environmental data analysis (Chen and Liu 2012). This interpolation method simply creates an assumption that close points from a known point are more identical than those points are staying apart (ESRI 2020).

To measure the predicted value of each point location, IDW assigns some weights based on the closest distance from a known point. The weights can be expressed as

$\lambda_{j}=\left(\frac{1}{{ }_{d_{i}^{P}}}\right) /\left(\sum_{j=1}^{n} \frac{1}{{ }_{d}^{P}}\right)$

where $d_{i}$ is the distance between known and unknown points, $p$ is the power parameter, and $n$ represents the number of sampled points used for the estimation. The main factor affecting the accuracy of IDW is the value of the power parameter $(p)$ and the search of the neighborhood (Babak and Deutsch 2009; Franke 1982; Shepard 1968).

\section{Results}

COVID-19 infection rate

As of May 22, 2020, about 6245 COVID-19 cases were confirmed in Dhaka city. The graph shows that this virus infection has affected all areas of the city and the increase in cases from May 06 to May 18, 2020 (Fig. 3).

Descriptive statistical analysis of all parameters

The annual average concentrations of air pollution, geometeorological, and social parameters are shown in Table 2. The mean annual average concentrations of $\mathrm{PM}_{2.5}\left(83.98 \mu \mathrm{g} / \mathrm{m}^{3}\right), \mathrm{NO}_{2}\left(427.29 \mathrm{~nm}^{2}\right), \mathrm{SO}_{2}$ (89.18 ppm), $\mathrm{CO}$ (93.10 ppm), and $\mathrm{O}_{3}(238.40 \mathrm{ppm})$ were above the national level threshold. The minimum and maximum ranges of digital elevation model and land surface temperature were $6-14 \mathrm{~m}$ and $20-27{ }^{\circ} \mathrm{C}$, respectively. The mean annual rainfall and wind speed were $275 \mathrm{~mm}$ and $0.96 \mathrm{mph}$, respectively, in the study area. In the social parameters, $0-1878$ persons were found per square kilometer, while the mean poverty and literacy rates were $70 \%$ and $74 \%$, respectively.

\section{Geographical Weighted Regression parameters}

Three Geographical Weighted Regression models were executed in order to understand the statistical and spatial relationships between the COVID-19 infection rate (dependent variable) and the 17 independent variables of air pollution, geo-meteorological, and social data. After running these multi-regression models, significant model fitting results such as estimated coefficient, standard error, $T, p$ value, and $r^{2}$ in the 3 sets of parameters are listed (Table 3).

In the air pollution data, $\mathrm{PM}_{2.5}(0.64), \mathrm{NO}_{2}(0.11)$, AOT (0.81), $\mathrm{SO}_{2}(0.20)$, and $\mathrm{O}_{3}(2.25)$ parameters had positive coefficient while $\mathrm{CO}(-0.56)$ and water vapor $(-3.04)$ had negative coefficient values. Standard error calculates the distance between each of the data points and its predicted value in a model. The model used in this study estimated a very small standard error in all independent variables (less than 1). There were only 2 negative parameters $\mathrm{CO}(-1.9)$ and water vapor (3.89) found in the $T$ result. Among the 7 air pollution parameters, 5 were statistically significant $\left(R^{2}\right)$ to the COVID-19 infection rate. $\mathrm{PM}_{2.5}$, AOT, and $\mathrm{O}_{3}$ statistically posed a significant positive effect on the COVID19 infection rate at a $95 \%$ confidence level. On the other hand, $\mathrm{CO}$ and wind vapor had negative coefficient with the COVID-19, but interestingly, both of them were statistically significant at $p,-0.01$. These results assumed that a 1 unit increase in the 5 parameters might increase the COVID-19 attack or mortality rates in 


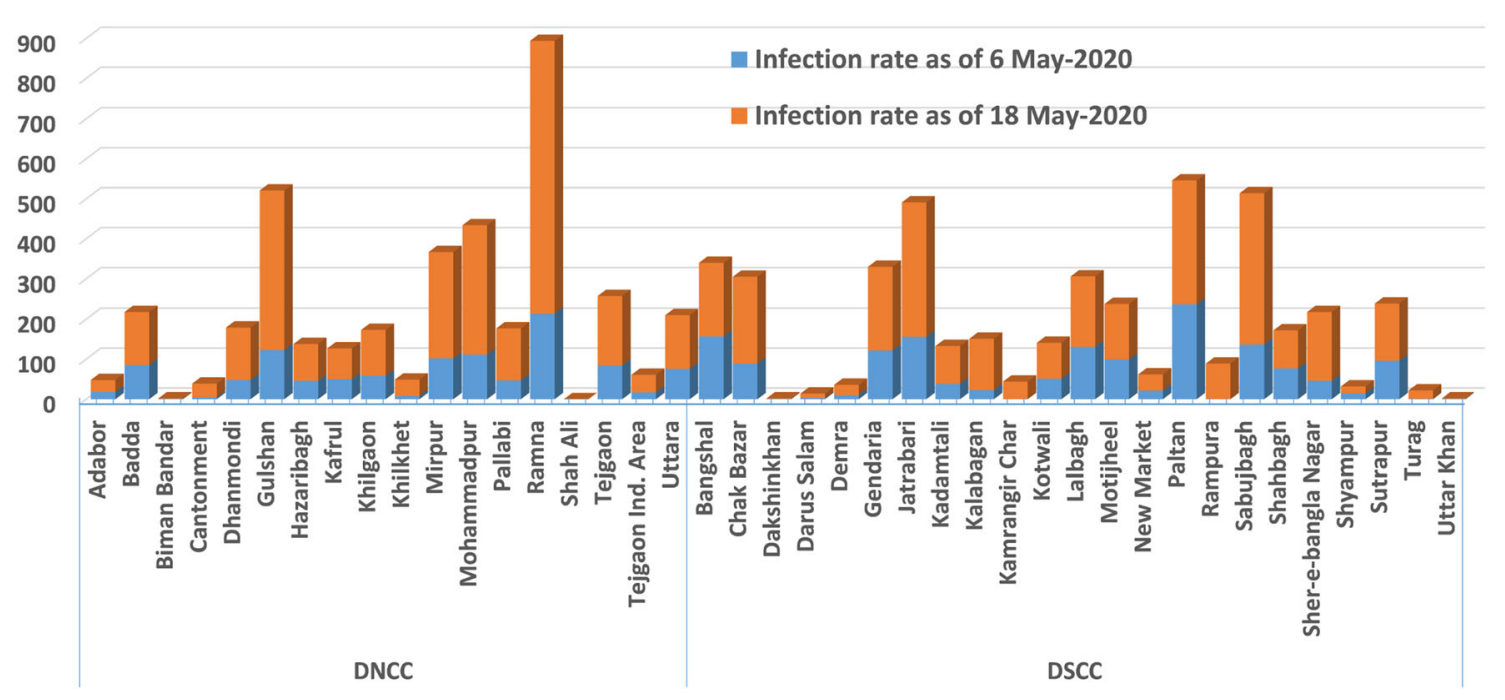

Fig. 3 Location-wise confirmed COVID-19 cases in both Dhaka North City and Dhaka South City Corporations (Bangladesh Covid-19 Update (2020)

Dhaka City. This model calculated a strong $R^{2}(0.84)$, which indicates that $84 \%$ of the COVID-19 attack is explained by the 7 air pollution parameters.

Five parameters were used for the geometeorological data, of which only water pressure $(-0.260)$ had a negative coefficient value. All other parameters like DEM (0.361), LST (0.236), rainfall (0.439), and wind speed $(0.212)$ had a positive influence on the dependent variable by showing a robust $R^{2}$ (0.73). This model explained about $73 \%$ variation in the independent variables responsible for COVID-19 infection rates. All values extracted from the standard

Table 2 The annual average of the key variables used in this study

\begin{tabular}{|c|c|c|c|c|c|c|c|c|}
\hline Theme & Variables & Mean & Std error & Standard deviation & Range & Min & Max & Sum \\
\hline \multirow[t]{7}{*}{ Air pollution parameters } & $\mathrm{PM}_{2.5}$ & 83.98 & 0.04 & 0.40 & 2.05 & 83.06 & 85.11 & 7222.66 \\
\hline & $\mathrm{NO}_{2}$ & 427.29 & 1.86 & 17.21 & 83.95 & 373.87 & 457.82 & $36,746.62$ \\
\hline & AOT & 0.45 & 0.00 & 0.01 & 0.05 & 0.42 & 0.46 & 38.46 \\
\hline & $\mathrm{SO}_{2}$ & 89.18 & 1.02 & 9.43 & 41.87 & 47.24 & 89.11 & 5089.84 \\
\hline & $\mathrm{CO}$ & 93.10 & 0.02 & 0.15 & 0.78 & 92.94 & 93.72 & 8006.90 \\
\hline & Water vapor & 2.39 & 0.00 & 0.00 & 0.00 & 2.39 & 2.39 & 205.54 \\
\hline & $\mathrm{O}_{3}$ & 238.40 & 0.02 & 0.23 & 0.87 & 237.96 & 238.83 & $20,502.62$ \\
\hline \multirow[t]{5}{*}{ Geo-meteorological parameters } & DEM & 9.83 & 0.25 & 2.27 & 8.02 & 6.20 & 14.22 & 845.33 \\
\hline & Wind pressure & 2.00 & 0.01 & 0.07 & 0.26 & 1.88 & 2.14 & 172.37 \\
\hline & LST & 26.17 & 0.01 & 0.10 & 0.46 & 25.87 & 26.33 & 2250.39 \\
\hline & Rainfall & 275.89 & 2.13 & 19.79 & 72.19 & 240.05 & 312.24 & $23,726.29$ \\
\hline & Wind speed & 0.56 & 0.00 & 0.04 & 0.10 & 0.50 & 0.60 & 48.26 \\
\hline \multirow[t]{5}{*}{ Social parameters } & Pop density & 336.15 & 37.79 & 350.42 & 1878.00 & 0.00 & 1878.00 & $28,909.32$ \\
\hline & Brickfield & 60.39 & 2.33 & 21.62 & 96.52 & 15.48 & 112.00 & 5193.29 \\
\hline & Poverty & 69.73 & 0.23 & 2.16 & 10.27 & 64.62 & 74.89 & 5996.87 \\
\hline & Land use & 2.91 & 0.11 & 1.04 & 4.00 & 1.00 & 5.00 & 250.00 \\
\hline & Literacy & 73.81 & 0.71 & 6.58 & 29.00 & 57.00 & 86.00 & 6348.00 \\
\hline
\end{tabular}


Table 3 Model fitting results derived from the Geographical Weighted Regression (GWR) showing the relationship between the COVID19 infection rate (dependent variable) and 17 independent variables

\begin{tabular}{|c|c|c|c|c|c|c|}
\hline \multirow[t]{2}{*}{ Theme } & \multirow[t]{2}{*}{ Parameters (independent) } & \multicolumn{5}{|c|}{ Model fitting results (COVID-19 as dependent variable) } \\
\hline & & Estimated coefficient & Standard error & $T$ & $p$ value & $R^{2}$ \\
\hline \multirow[t]{7}{*}{ Air pollutant } & $\mathrm{PM}_{2.5}$ & 0.645 & 0.295 & 2.187 & 0.029 & \multirow[t]{7}{*}{.84} \\
\hline & $\mathrm{NO}_{2}$ & 0.112 & 0.305 & 0.368 & 0.713 & \\
\hline & AOT & 0.816 & 0.322 & 2.531 & 0.011 & \\
\hline & $\mathrm{SO}_{2}$ & 0.200 & 0.416 & 0.481 & 0.630 & \\
\hline & $\mathrm{CO}$ & -0.562 & 0.296 & -1.900 & 0.057 & \\
\hline & Water vapor & -3.043 & 0.784 & -3.881 & 0.015 & \\
\hline & $\mathrm{O}_{3}$ & 2.257 & 0.556 & 4.059 & 0.013 & \\
\hline \multirow[t]{5}{*}{ Geo-meteorological } & DEM & 0.361 & 0.105 & 3.428 & 0.012 & \multirow[t]{5}{*}{.73} \\
\hline & Wind pressure & -0.260 & 0.162 & -1.604 & 0.015 & \\
\hline & LST & 0.236 & 0.126 & 1.883 & 0.040 & \\
\hline & Rainfall & 0.439 & 0.163 & 2.693 & 0.017 & \\
\hline & Wind speed & 0.212 & 0.102 & 2.077 & 0.038 & \\
\hline \multirow[t]{5}{*}{ Social } & Pop density & 0.318 & 0.116 & 2.738 & 0.016 & \multirow[t]{5}{*}{.70} \\
\hline & Brickfield & 0.212 & 0.095 & 2.233 & 0.026 & \\
\hline & Poverty & -0.283 & 0.119 & -2.382 & 0.017 & \\
\hline & Land use & 0.165 & 0.104 & 1.591 & 0.112 & \\
\hline & Literacy & 0.047 & 0.098 & 0.481 & 0.630 & \\
\hline
\end{tabular}

error showed in the normal range while the water pressure $(-1.60)$ was negative in $T$ result. Moreover, among the 5 geo-meteorological parameters, DEM ( $p$ $<0.01)$, LST $(p<0.04)$, rainfall $(p<0.07)$, and wind speed $(p<0.03)$ were statistically significant with the COVID-19 infection rate. Therefore, these parameters have the potential to influence the infection of COVID-19 in Dhaka.

Poverty had negative values in the estimated coefficient $(-0.283)$ and $T$ result $(-2.382)$, although it was statistically significant $(p<0.01)$. On the other hand, population density, brickfield density, land use, and literacy rate had positive results in both the estimated coefficients and $T$ results. These 4 parameters showed a very small standard error, showing these accounted for $70 \%$ of the COVID-19 infection rate $\left(R^{2}=0.70\right)$ in this model. However, the other 2 social parameters like population density $(p<0.01)$ and brickfield $(p<0.02)$ were statistically significant in this regression model. Land use and literacy rate were not statistically significant.
Spatial relationship between the COVID-19 infection rate and air pollution, geo-meteorological, and social parameters

In order to understand the different spatial relationships among these factors through the advanced statistical lens, $r^{2}$, influence, and the $p$ values were derived from the Geographically Weighted Regression (GWR) model. The minimum and maximum $r^{2}$ values were 0.30 and 0.84 in the air pollution parameters respectively (Fig. 4a). The mean value was 0.39 which was mostly found in the south and middle zones of the study area. On the other hand, the mean $r^{2}$ value $(0.28)$ of geometeorological parameters was found in the middle, middle eastern, and southern parts of the study area keeping minimum and maximum values 0.18 and 0.73 , respectively (Fig. $4 \mathrm{c}$ ). The social parameters were essential predictors for establishing a relationship with the COVID-19 infection rate. The mean $r^{2}$ value (0.27) was found in the middle, middle eastern, and northwestern parts of the study area (Fig. 4b). While its standard deviation was 0.04 , the minimum and maximum values were 0.21 and 0.70 , respectively. 
(a) Coefficient of determination (R2) Air Pollution Parameters

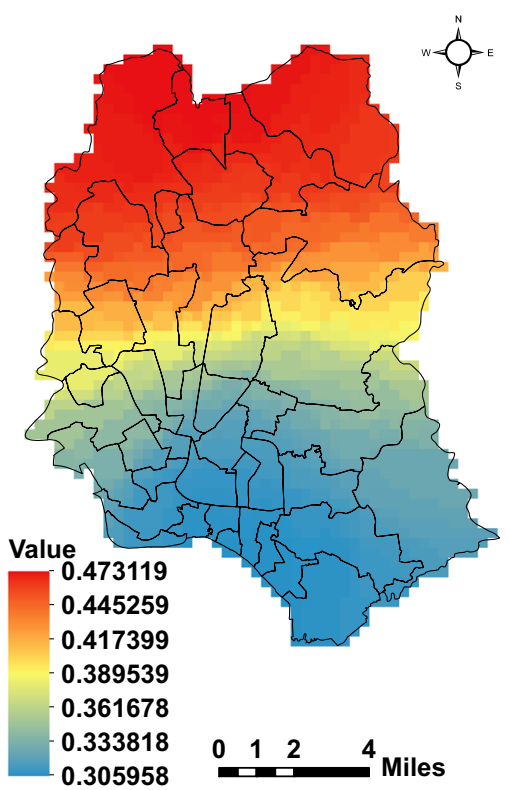

(b) Coefficient of determination (R2) Social Parameters

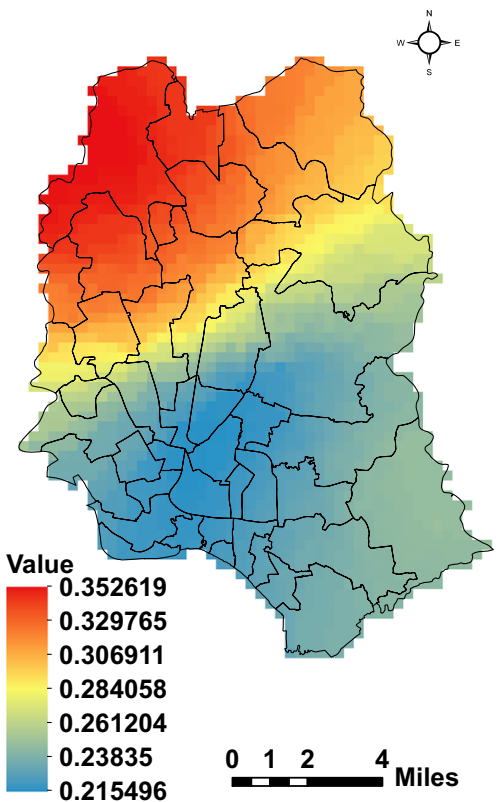

(c) Coefficient of determination (R2) Geo-meteorological Parameters

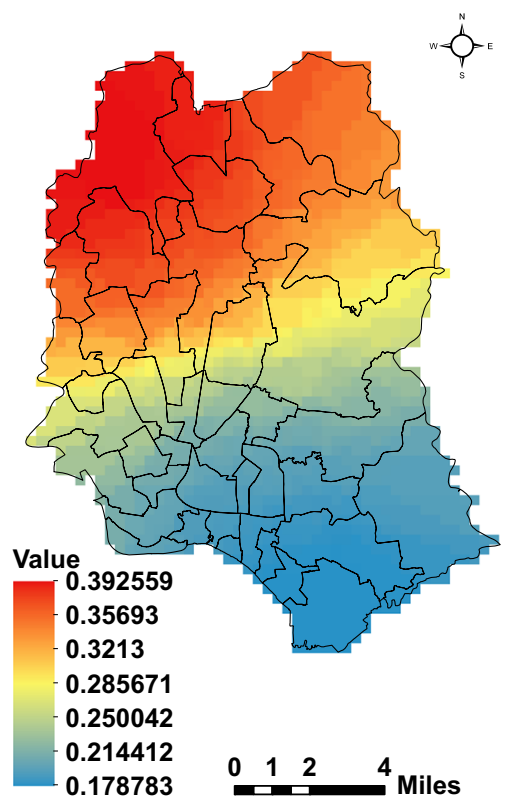

Fig. 4 Spatial distribution of $r^{2}$ in air pollution, social, and geo-meteorological parameters

The higher influence values of independent variables predict a good explanation for the dependent variable. In air pollution parameters, a number of influence zones in the north, eastern, western, and a few in the southern parts were found (Fig. 5a). Except for the middle part of the study area, the influence statistics was quite (a) Influence- Cook's Distance Air Pollution Parameters

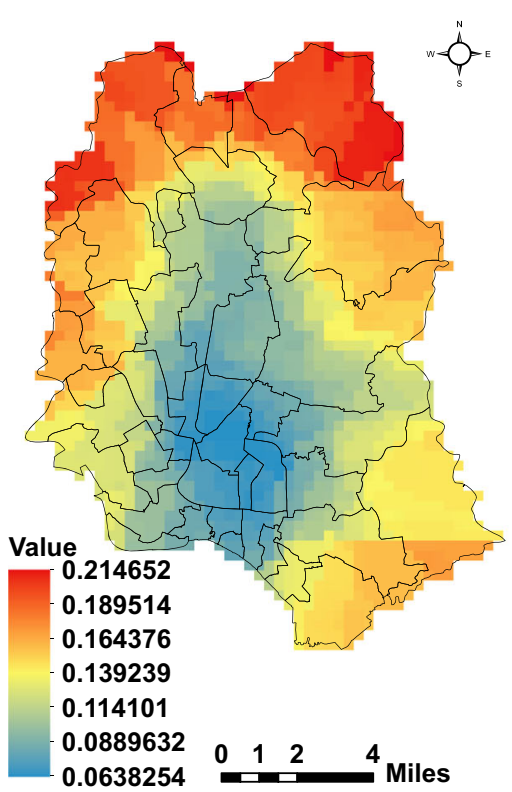

(b) Influence- Cook's Distance Social Parameters

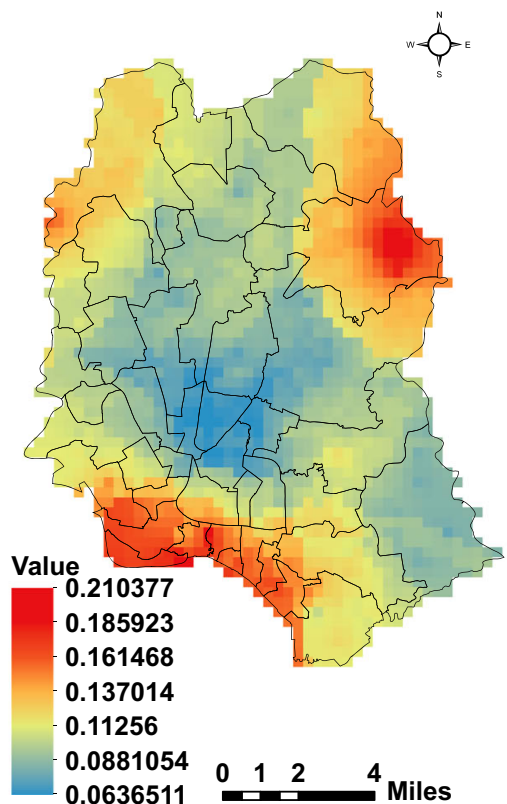

(c) Influence- Cook's Distance Geo-meteorological Parameters

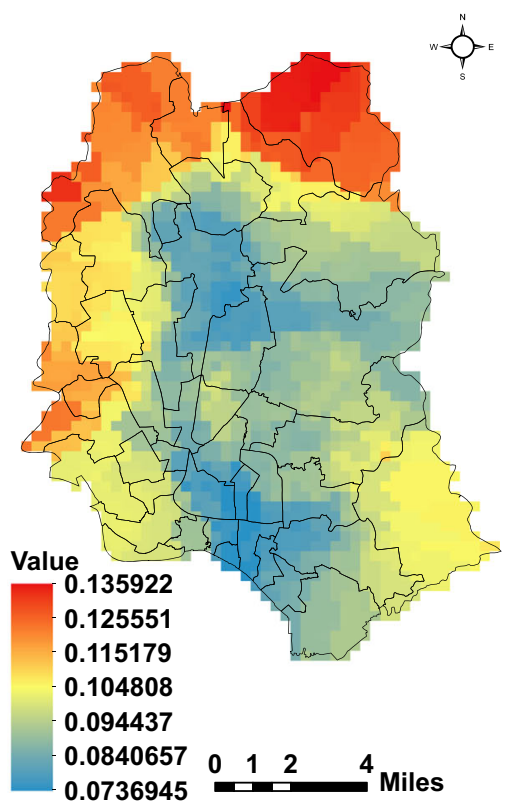

Fig. 5 Spatial distribution of influence in air pollution, social, and geo-meteorological parameters 
significant across the study area keeping 0.13 and 0.03 in mean and standard deviation, respectively. The influence of geo-meteorological parameters was significantly higher in the study area, except Cantonment, Gulshan, Ramna, Kafrul, Shahbag, Bangshal, Chakbazar, Gendaria, and Shyampur areas (Fig. 5c). The minimum and maximum values of geo-meteorological parameters were 0.07 and 0.13 , respectively, while its mean value was 0.09 . Social parameters were quite influential in the north-eastern and southern parts. The minimum and maximum values of social parameters were 0.06 and 0.21 , respectively, while the mean value was 0.10 (Fig. $5 b)$. A strong influence of social parameters was found in the southern part of the city. (a) Statistical Significance of AOT $(p<0.05)$

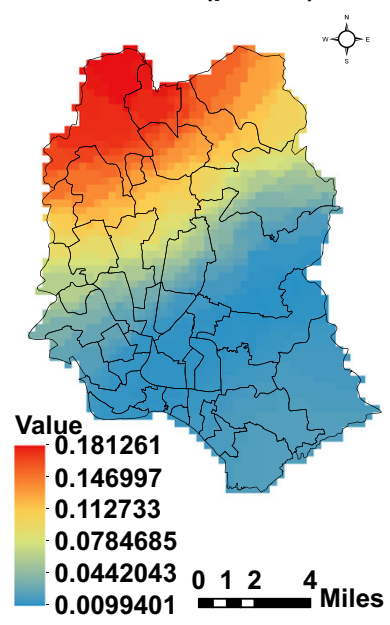

(b) Statistical Significance of $\mathrm{CO}(\mathrm{p}<0.05)$

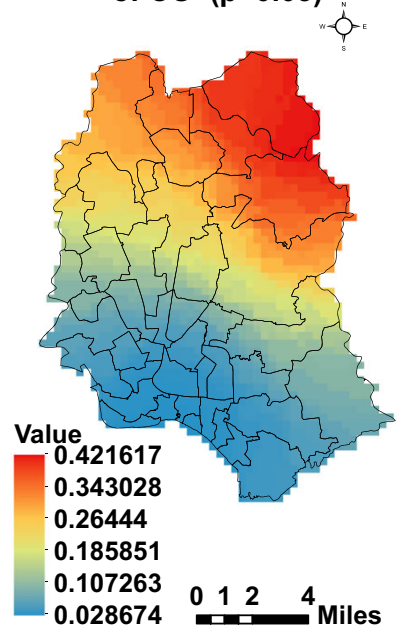

(c) Statistical Significance of $N(p<0.05)$

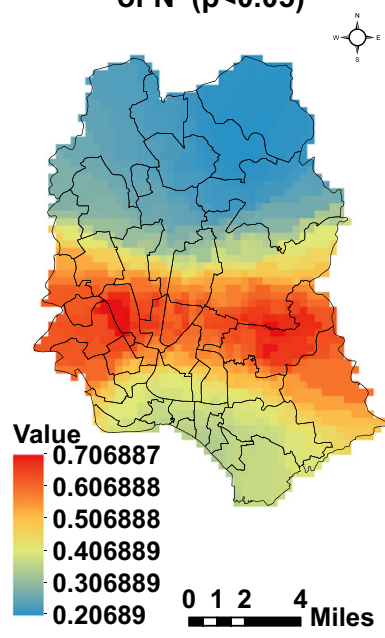

(d) Statistical Significance of $03(p<0.05)$

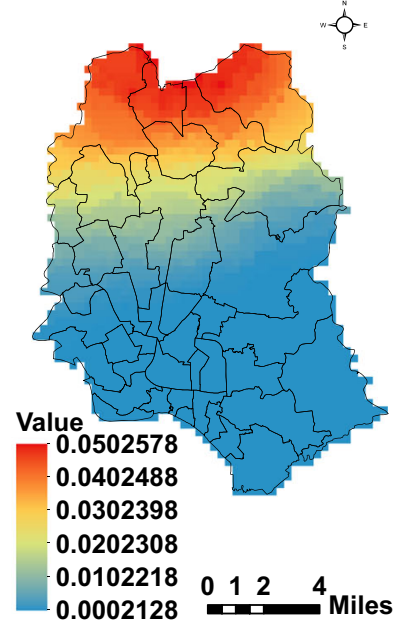

(e) Statistical Significance of PM2.5 $(p<0.05)$

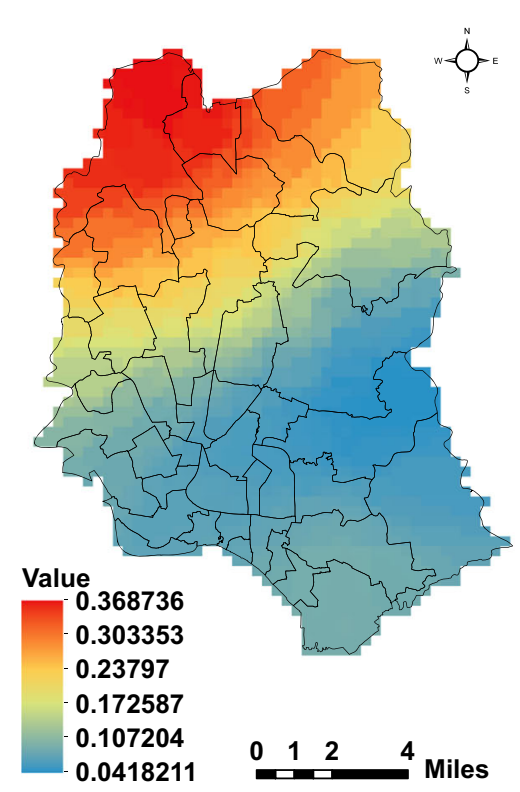

(f) Statistical Significance of $\mathrm{SO} 2$ $(p<0.05)$

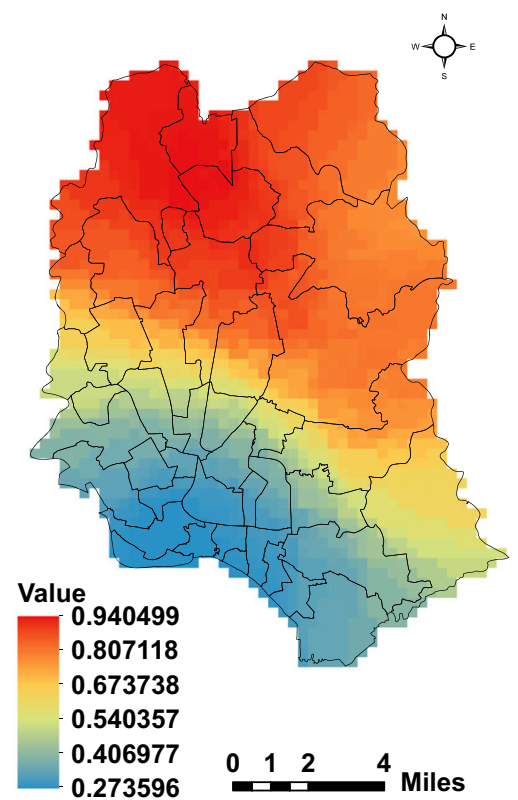

(g) Statistical Significance of WV $(p<0.05)$

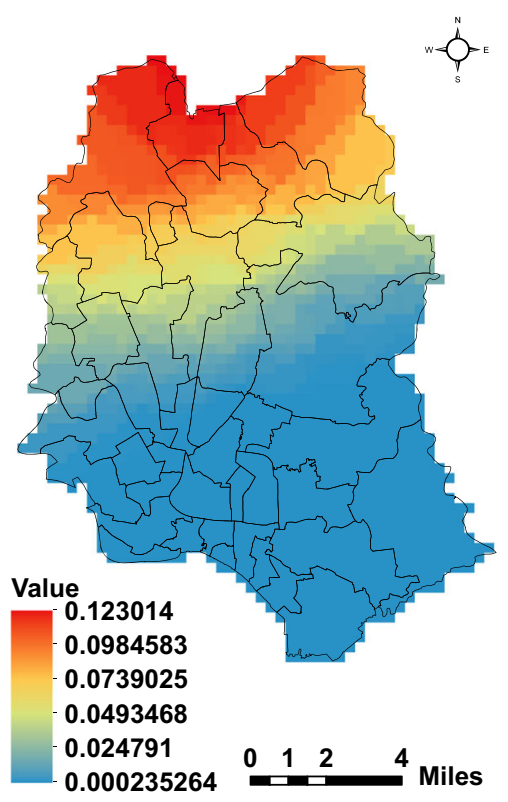

Fig. 6 Spatial distribution of $p$ value in air pollution parameters 
(a) Statistical Significance of DEM $(p<0.05)$

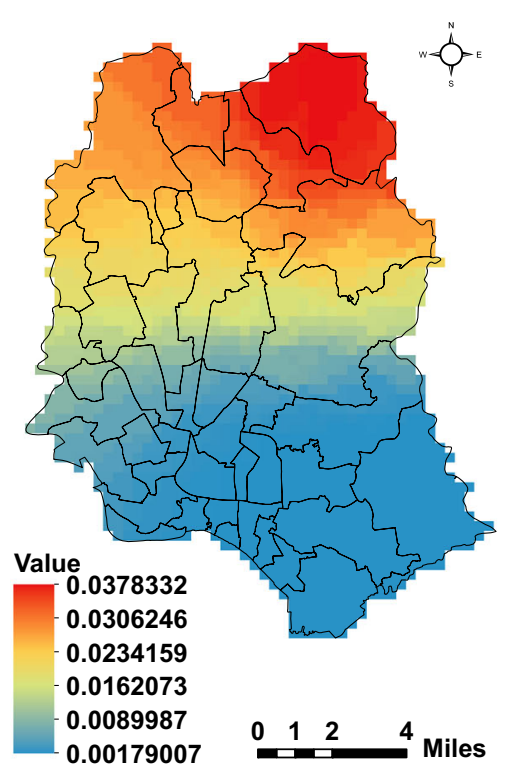

(d) Statistical Significance of Wind speed $(p<0.05)$

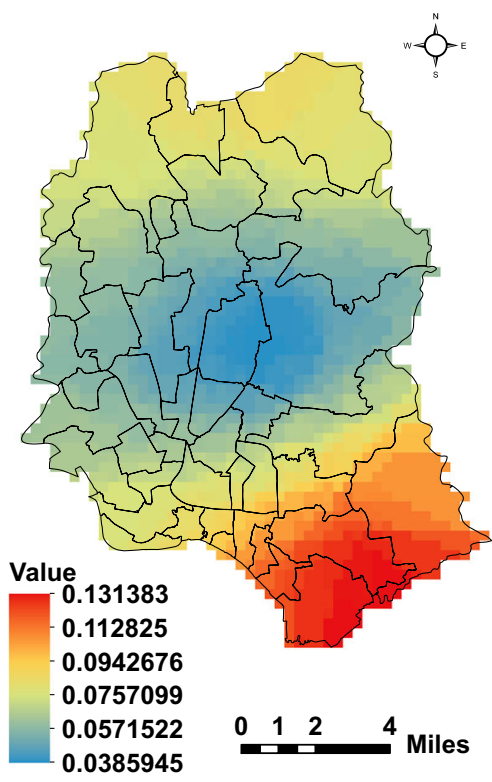

(b) Statistical Significance of LST $(p<0.05)$

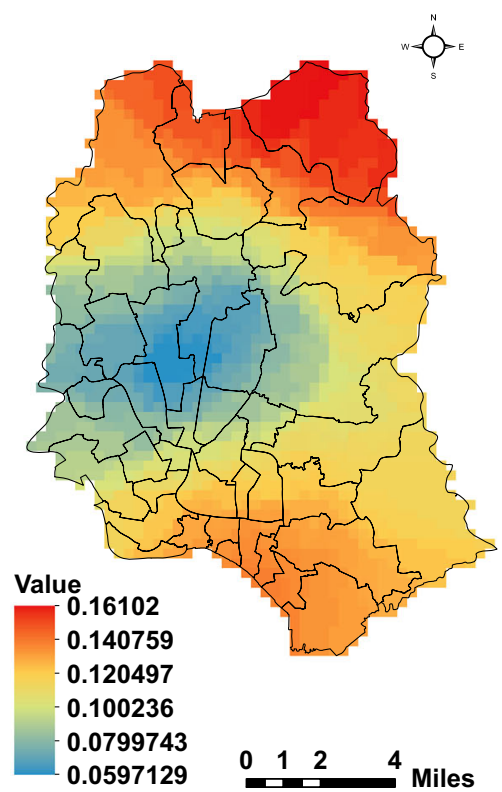

(c) Statistical Significance of Rainfall $(p<0.05)$

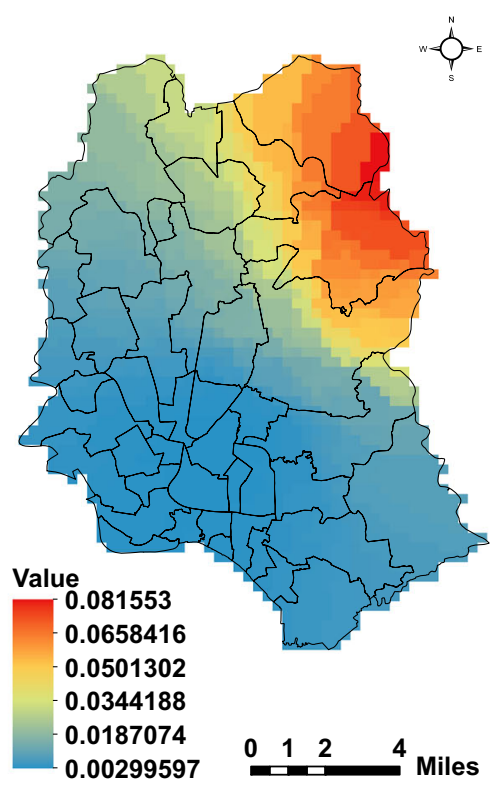

(e) Statistical Significance of Wind pressure $(p<0.05)$

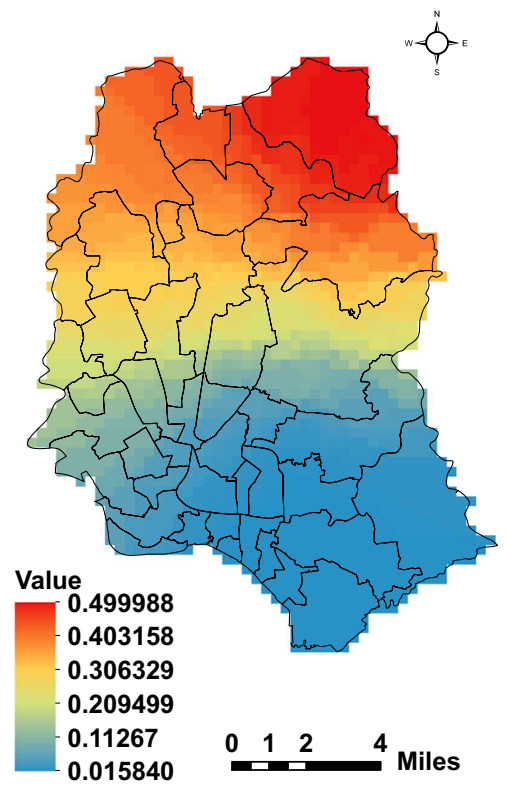

Fig. 7 Spatial distribution of $p$ value in geo-meteorological parameters

The $p$ value is an important parameter in this study. There were some strong relationships between COVID19 infection rate data and air pollution, geo-meteorological, and social parameters. Strong statistical evidences of $p$ values in $\mathrm{PM}_{2.5}(<0.02)$, AOT $(<0.01), \mathrm{CO}(<$
$0.05)$, water vapor $(<0.01)$, and $\mathrm{O}_{3}(<0.01)$ in the air pollution parameters were found. Most of these parameters and their correlated $p$ values were found in the middle, south, south-western, and south-eastern parts of the study area. Interestingly, $\mathrm{O}_{3}$, AOT, and wind vapor 
(a)Statistical Significance of Brickfield $(p<0.05)$

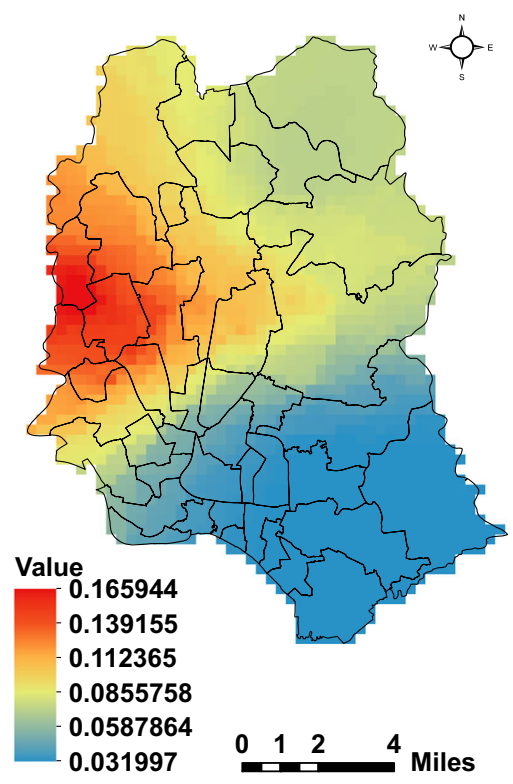

(d) Statistical Significance of Pop Density $(p<0.05)$

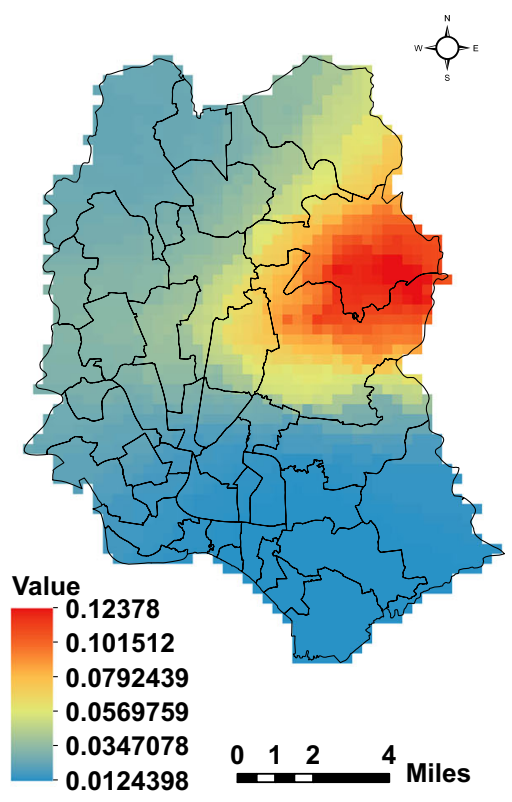

(b) Statistical Significance of Land use $(p<0.05)$

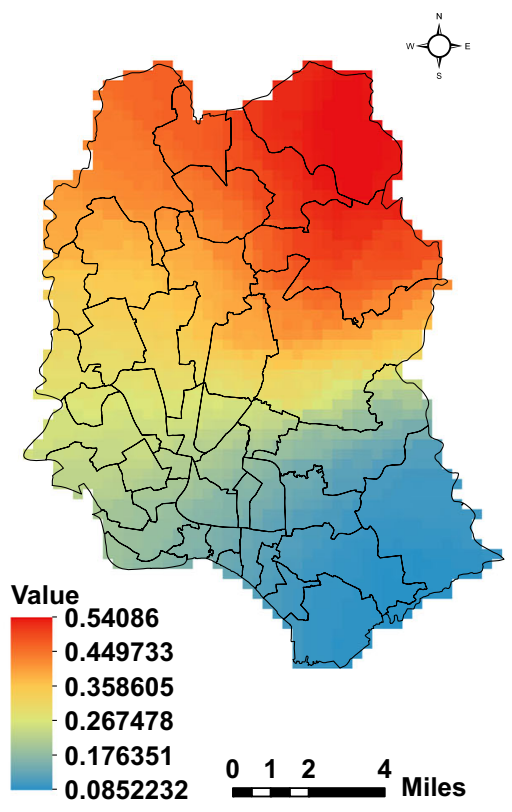

(c) Statistical Significance of Literacy $(p<0.05)$

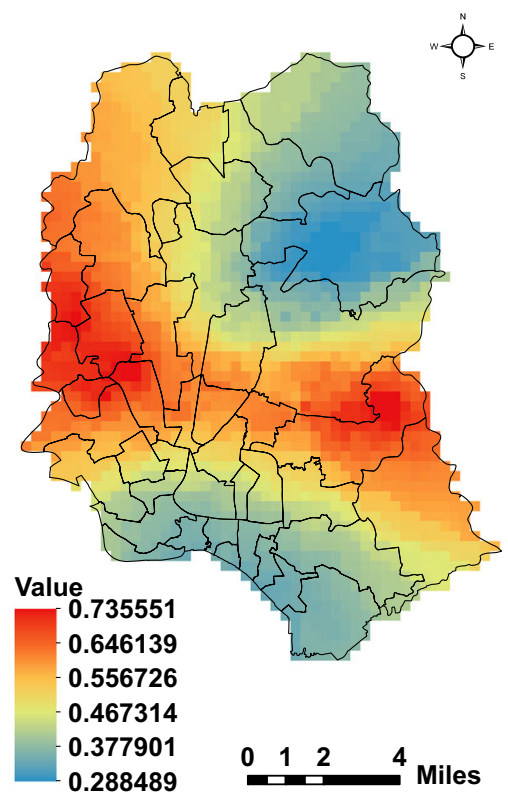

\section{(e)Statistical Significance of Poverty $(p<0.05)$}

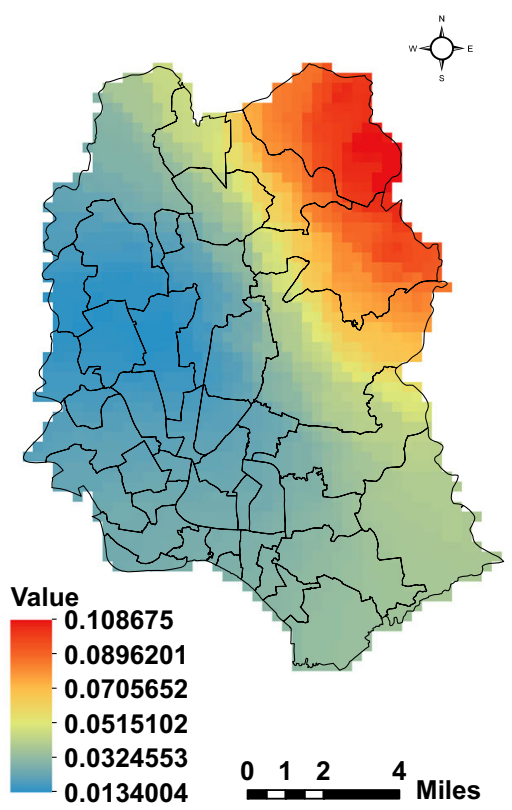

Fig. 8 Spatial distribution of $p$ value in social parameters

were found their strong prevalence over the whole study area (Fig. 6).

A number of geo-meteorological parameters selected in this model had some positive relationships with the COVID-19 infection rate. Digital elevation model (DEM), land surface temperature (LST), rainfall, and wind speed had statistically significant $p$ values of $<0.01,<0.04,0.01$, and $<0.03$, respectively. Figure 7 showed a spatial distribution of $r^{2}$ map in all of the geo-meteorological parameters in 
where DEM, LST, wind speed, and wind pressure were found in the south, middle, middle eastern, and southern parts in the area, respectively. Rainfall had a great statistical influence on the dependent variable, which covered $90 \%$ of the study area.

Population density $(p<0.01)$, brickfield $(p<0.02)$, and poverty $(p<0.01)$ had significant roles on COVID19 infection rate in the study area. In terms of the geographical distribution of population density and poverty, about $90 \%$ of areas were covered by these factors (Fig. 8). On the other hand, brickfield was highly visible in the southern part of the study area in which the COVID-19 infection rate was higher. Land use and literacy rate were not statistically significant, but these had a positive coefficient with the dependent variable.

\section{Discussion}

The main objective of this study was to investigate the spatial relationships between COVID-19 infection rate and air pollution, geo-meteorological, and social parameters in the study area using Geographical Weighted Regression and spatial analysis of GIS. Different results from the 3 models and their 17 parameters of 3 thematic areas were found and described in the section below.

\section{COVID-19 infection rate and air pollution parameters}

Out of 7 air pollution parameters, 5 parameters $\mathrm{PM}_{2.5}$ $(p<0.02)$, AOT $(p<0.01), \mathrm{CO}(p<0.05)$, water vapor $(p<0.01)$, and $\mathrm{O}_{3}(p<0.01)$ were highly correlated with COVID-19 infection rate in this study. These pollutants are highly associated with the impacts on urban public health in Dhaka (Begum et al. 2013). Since COVID-19 mainly causes respiratory failure, it is no surprise that air pollution has an influence on COVID-19 infection rates. (Wu et al. 2020b) used temporal $\mathrm{PM}_{2.5}$ data from 2000 to 2016 and the COVID-19 mortality rate for executing a negative binomial mixed model in order to calculate the mortality rate ratio (MRR) in the USA. They found that $1 \mu \mathrm{g} / \mathrm{m}^{3}$ increases of $\mathrm{PM}_{2.5}$ can enhance $8 \%$ of COVID-19 death with a 95\% confidence interval in Mid-Atlantic, upper Midwest, and Gulf Coast areas. In this study, $\mathrm{PM}_{2.5}$ had a significant positive correlation with COVID-19 $(p<0.02)$ with a $95 \%$ confidence level. Along with other particulates, $\mathrm{PM}_{10}, \mathrm{NO}_{2}$, and $\mathrm{O}_{3}$ were found as critical factors that attribute to mortality in Spain, in which relative risks (RRs) were connected with higher respiratory cases with CI 95\% (Ortiz et al. 2017).

$\mathrm{O}_{3}(p<0.01)$ was found as a strong factor that may influence the COVID-19 infection rate in this study. It is known that ozone generates oxidative stress and exposure to high ozone concentrations might reduce the lung lining fluid antioxidant level (Domingo and Rovira 2020; Manisalidis et al. 2020). $\mathrm{SO}_{2}$ and $\mathrm{NO}_{2}$ did not show a strong correlation and this may be due to slight increases in these pollutants during the pandemic. Sharma et al. (2020) looked at 5 air pollutants $\left(\mathrm{PM}_{10}\right.$, $\mathrm{PM}_{2.5}, \mathrm{CO}, \mathrm{NO}_{2}$, and $\mathrm{SO}_{2}$ ) in India during their lockdown period. They found these parameters had significant contribution to reducing the Excessive Risks (ER) due to COVID-19 mortality except for $\mathrm{SO}_{2}$, which showed negligible change.

Since air pollution is a risk factor for pulmonary diseases like asthma and respiratory infection, it is rightly considered to have a damaging impact on patients with COVID-19. A number of studies show a correlation between air pollution and COVID-19 in different countries (Pansini and Fornacca 2020). This study also found that there is a significant positive relationship between COVID-19 infection rate and $\mathrm{PM}_{2.5}$ but a negative relationship between CO in Dhaka. Yao et al. (2020) suggest that advanced absorption of the coronavirus on $\mathrm{PM}_{2.5}$ is the reason for the higher rate of death of COVID-19 in China. whereas in Dhaka Pavel et al. (2020) have generated Kendall and Spearman correlation test which states negative correlation for $\mathrm{PM}_{2.5}$ which is different to this study. This divergence may arise due to the difference in the time span of the data, Pavel and co-workers used data from March 2020 to June 2020 only while this study analyzed the factors for a longer period, namely, from 2010 to 2020 . The current study has found $\mathrm{NO}_{2}$ has a positive coefficient $(0.112)$ but interestingly has no significance $(P>0.05)$ with the determination of the COVID-19 infection rate whereas, $\mathrm{Li}$ et al. (2020a) found the strong significance of $\mathrm{NO}_{2}$ $(p<0.01)$ in China specially in Wuhan and XiaoGan. SENTINEL-5 which deliver comprehensible information on atmospheric variables shows that the emission of $\mathrm{NO}_{2}$ is much higher in China than Bangladesh which may explain the result of this study.

Variables like relative humidity, temperature, and the volume of water vapor changes display a significant negative association of water vapor $(\beta=-3.043, p<0.01)$ with COVID-19 infection rates in this study and this is consistent with a recent study done where water vapor shows same 
association $(p<0.01)$ with COVID-19 infection rates (Wang et al. 2020). The distribution of AOT or AOD does vary from country to country and also between the exposer and pre-exposer period. Our test statistic indicates that there is a significant impact of AOT $(p<0.01)$ on COVID-19 infection rate and this agrees with results in Italy, Germany, and Spain particularly on longer exposure period. Three out of 7 models indicate AOT being an important determinant in deciding the mortality rate of COVID-19 (Li et al. 2020b). Another potential variable that may instigate the rate of infection is ozone. Similar to our study, another study also observed the same result that ozone has significant positive association with the rate of infection or new cases of COVID-19 (Adhikari and Yin 2020).

COVID-19 infection rate with geo-meteorological parameters

Meteorological factors are the key drivers for controlling infectious diseases in different parts of the world (Șahin 2020). However, these triggering factors may behave differently for the daily mortality cases in a different climatic zone. For example, in tropical Brazil, high mean temperature and intermediate relative humidity might be responsible for the COVID-19 outbreak (Auler et al. 2020). However, these triggering factors may behave differently for the daily mortality cases in a different climatic zone. For example, in tropical Brazil, high mean temperature and intermediate relative humidity might be responsible for the COVID-19 outbreak (Auler et al. 2020). In this present study, DEM $(p<0.01)$, wind pressure $(p<0.01)$, LST $(p<0.04)$, rainfall $(p<0.01)$, and wind speed $(p<0.03)$ were significantly associated with the COVID-19 infection rate. $\mathrm{Wu}$ et al. (2020b) revealed that land temperature and relative humidity were linked to the daily new cases and deaths of COVID-19. A $1{ }^{\circ} \mathrm{C}$ increase in temperature and $1 \%$ increase in relative humidity were associated with a reduced mortality rate by $3.08 \%$ and $0.85 \%$ reduction of daily new cases of COVID-19 infection. In this study, a $1{ }^{\circ} \mathrm{C}$ increase in temperature leads to a $10 \%$ increase in COVID-19 infection rates.

Qi et al. (2020) and Wu et al. (2020b) used a Generalized Additive Model (GAM) to compute the provincespecific relations among climatological variables and the daily cases of COVID-19 in China. Their studies found that the temperature and humidity presented negative associations with the COVID-19, while a significant interaction can be found between temperature and humidity. This is different to our study because the temperature had a positive relationship with COVID19 infection rates.

Ma et al. (2020) and Qi et al. (2020) established a relationship between daily death numbers of COVID-19 with meteorological parameters and air pollution data from 20 January 2020 to 29 February 2020 in Wuhan, China, which was the starting point of the global pandemic. They revealed a positive correlation $\left(r^{2}=0.44\right)$ between COVID-19 death and temperature. This is similar to our study because we had a positive correlation between COVID-19 and temperature $\left(r^{2}=0.73\right)$.

The number of researches conducted in recent times indicates that geo-meteorological variables have an influence on COVID-19 infection rate (Zhou et al. 2020). In this study, all five geo-meteorological variables are highly significant with a $R^{2}$ value of 0.73 which implies that the $73 \%$ variations of COVID-19 infection rate can be explained by these parameters. Digital Elevation Model (DEM) which uses 3D computer graphics information about surface height has shown a significant positive relationship $(\beta=0.361, p<0.01)$ between DEM and infection rate which means that if land elevation increases by $1 \mathrm{~m}$, it will lead to an increase in the infection rate of COVID-19 by $36.1 \%$. Interestingly, a study by (Arias-Reyes et al. 2020) shows an opposite outcome as they found a strong negative relationship between land altitude and occurrences of COVID-19 cases. The differences may be due to discrepancies in altitude that depends on many things such as land, rock formations, and buildings - specially in a dense, urban environment (Abdulrazzaq et al. 2019). Further studies are needed to understand this relationship with elevation and COVID-19 infection rate.

Another important determining factor of COVID-19 infection rate is Land Surface Temperature (LST). This study showed that a $1{ }^{\circ} \mathrm{C}$ increase in temperature is linked with $36.1 \%(p<0.01)$ increase in infection rate of COVID-19 which agrees with a recent study which shows that a $1{ }^{\circ} \mathrm{C}$ increase in temperature leads to $12.1 \%(p<0.0001)$ increases in new COVID-19 cases. Moreover, the researchers have also concluded that rainfall and wind speed have a positive association with the infection rate (Adhikari and Yin 2020). A study in turkey (Şahin 2020) has found that the average wind speed of 14 days has the highest correlation with the number of COVID-19 cases. But this positive associations between wind speed and number of COVID-19 cases are bit of complicated as several other studies indicates a negative 
association between wind speed and Corona Virus infection rates. It can be argued that low wind speed leads to higher cases of COVID-19 infection rate, as the low wind speed assists in keeping the virus in the same area for several hours (Ahmadi et al. 2020; Rendana 2020). Another study conducted to identify the impact of weather and air pollution on COVID-19 transmission based on 3739 worldwide locations found a positive correlation between air pressure and transmission of COVID-19 infection rate which was unlike our study as we see a negative correlation between wind pressure and the rate of infection of COVID-19 (Xu et al. 2020). The difference in results may be a localized matter as our study focused on Dhaka while the literature study contained 3739 global locations.

COVID-19 infection rate with social parameters

Population density is an important parameter with relation to COVID-19 infection (Rocklöv and Sjödin 2020). Desai (2020) showed that areas with highdensity population have more confirmed COVID-19 cases. For analyzing COVID-19 data, population density information needs to be used as one of the controlling variables and it was suggested that investigation should be done at local, regional, and national levels separately (Pedrosa 2020). Hu et al. (2013) calculated a relationship between influenza mortality rates and population densities and found that the higher density shows higher reported mortality. In the present study, population density $(p<0.01)$, brickfield density $(p<0.02)$, and poverty $(p<0.01)$ had high coefficients to COVID-19 infection rate.

In and around the Dhaka, there are about 917 brickfields covering $26.64 \mathrm{~km}^{2}$ (Hassan et al. 2019), which are the primary sources for air pollution in the city. These brickfields emit 23,300 tons from $\mathrm{PM}_{2.5}$, 15,500 tons of sulfur dioxide $\left(\mathrm{SO}_{2}\right), 302,000$ tons of carbon monoxide (CO), 6000 tons of black carbon, and 1.8 million tons of $\mathrm{CO}_{2}$ (Guttikunda et al. 2013). Several research reports mentioned that these brickfields not only affect the atmospheric quality of the city but also a responsible factor for other environmental pollutions and are a public health hazard (Saha and Hosain 2016; Skinder et al. 2014; Tusher et al. 2019). The strong correlation of brickfield density and COVID-19 infection rates indicated in this study is alarming in a city like Dhaka.
Similar to air pollution and geo-meteorological factors, social factor is an important aspect in determining its impact on COVID-19. In our study, we have selected five social factors among them except land use and literacy; other three factors are highly significant which indicate that there is association between COVID-19 infection rate and independent variables with a $R^{2}$ value of 0.70 . Which infers that $70 \%$ variation in COVID-19 can be explained by the social parameters.

One essential diffusion path of COVID-19 infections is contact between infected and non-infected people. To reduce the morbidity rate of COVID-19, the one preventive measure that has been applied worldwide is to maintain social distance and to ensure that the imposition of lockdown and uses of mask is practiced. This is where population density comes in. As we can assumed it is hard to maintain the social distance when the population density is high leading to the rapid spread of the coronavirus. Our present study confirms this assumption as we derive a strong positive association $(p<0.01)$ between population density and COVID-19 infection rate indicating higher population density surges the rate of infection. Several previous studies also reached similar findings (Arias-Reyes et al. 2020; Nakada and Urban 2020; You et al. 2020). We have found a strong association $(p<0.01)$ between poverty and COVID-19 morbidity rate as people with poor income tend to be more exposed to all health hazards. Mukherji (2020) have concluded that places where the inequality between low and high income is high observes a higher indisposition rate of COVID-19.

Literacy rate $(p>0.63)$ was not one of the significant social parameters of our study. This is in contradiction to another study which observed a positive association between poor education and high rates of COVID-19 cases (Harlem and Lynn 2020). It is presumed that with higher literacy rate will lead to more access to information and awareness. In Dhaka, there has been an intense campaign by the government and non-government organizations to educate the public about COVID-19 and our results suggest that this could be the reason why literacy rate is not a significant parameter in the study.

The present study is an attempt to assess the spatial relationship of COVID-19 infection rate with air pollution, geo-meteorological, and social parameters. To the 
best of our knowledge, this study is among the very few studies concerning coronavirus in Bangladesh. We have examined 17 different independent variables and their possible association with the infection rate of COVID19. We have used data from 2010 to 2020 while other studies have used very short-term data for the estimation of infection rate. One of the limitations of our study is that we only investigated the COVID cases in Dhaka while other cities of the country were ignored. Several other factors such as age, gender, ethnicity, nature of food intake, and chronic diseases may play an important role in defining the COVID-19 cases so there is further scope of research which may help better understand the nature of COVID-19.

\section{Summary and conclusion}

The spatial relationships between the COVID-19 infection rate and 17 independent parameters of air pollution, geo-meteorological, and social in the study area using Graphically Weighted Regression Model and GIS platform were studied. This paper has found a number of significant key results that can be summarized as follows:

- The mathematical model of COVID-19 and air pollution $\left(R^{2}=84 \%\right)$, geo-meteorological $\left(R^{2}=73 \%\right)$, and social parameters $\left(R^{2}=70 \%\right)$ has a high goodness-of-fit

- Air pollution parameters $\mathrm{PM}_{2.5}(p<0.02)$, AOT $(p<0.01), \mathrm{CO}(p<0.05)$, water vapor $(p<0.01)$, and $\mathrm{O}_{3}(p<0.01)$ were highly correlated with COVID-19 infection rate

- Digital Elevation Model $(p<0.01)$, wind pressure $(p<0.01)$, land surface temperature $(p<0.04)$, rainfall $(p<0.01)$, and wind speed $(p<0.03)$ of geometeorological parameters were associated with the COVID-19 attack

- Social parameters of population density $(p<0.01)$, brickfield density $(p<0.02)$, and poverty $(p<0.01)$ were highly coefficient as the key independent variables to the COVID-19 infection rate

- The North, Middle, and Southern parts of the study area are more susceptible to COVID-19 infection rate

It is hoped that the authorities in Dhaka can utilize these findings in order to formulate new management strategies for reducing infectious diseases like COVID19. In a small country like Bangladesh, where resources are limited and targeted and precise approaches based on scientific analysis as presented in this study will help in controlling the serious pandemic situation we face today. This study will also be useful for researchers who are working on understanding the latent and visible relationships between the COVID-19 and its associated variables like pollution, environmental, and social aspects. The methodology can be replicated to a similar country or region considering the local micro-climatic environment. Future studies will have more variables including ecological, meteorological, and social (GDP, BMI Global Health Index) to model and understand the spread of COVID-19 in an urban environment.

Acknowledgments This study uses a number of free databases from the National Aeronautics and Space Administration (NASA), European Space Agency (ESA), Bangladesh Bureau of Statistics, and Bangladesh Ministry of Health. The key authors of the paper would like to convey acknowledgment for their continued support in conducting research.

\section{Compliance with ethical standards}

Conflict of interest The authors declare that they have no conflict of interest.

\section{References}

Abdulrazzaq, Z. T., Hasan, R. H., \& Aziz, N. A. (2019). Integrated TRMM data and standardized precipitation index to monitor the meteorological drought. Civil Engineering Journal, 5(7), 1590-1598. https://doi.org/10.28991/cej-2019-03091355.

Adhikari, A., \& Yin, J. (2020). Short-Term effects of ambient ozone , PM2.5, and meteorological factors on COVID-19 confirmed cases and deaths in Queens, New York. International Journal of Environmental Research and Public Health, 1-13. https://doi.org/10.3390 /ijerph17114047.

Ahmadi, M., Sharifi, A., Dorosti, S., Jafarzadeh Ghoushchi, S., \& Ghanbari, N. (2020). Investigation of effective climatology parameters on COVID-19 outbreak in Iran. Science of the Total Environment, 729, 1-7. https://doi.org/10.1016/j. scitotenv.2020.138705.

Ahmed, B., Hasan, R., \& Maniruzzaman, K. M. (2014). Urban morphological change analysis of Dhaka City, Bangladesh, using space syntax. ISPRS International Journal of GeoInformation, 3(4), 1412-1444. https://doi.org/10.3390 /ijgi3041412.

Ahmed, B., Kamruzzaman, M. D., Zhu, X., Shahinoor Rahman, M. D., \& Choi, K. (2013). Simulating land cover changes and their impacts on land surface temperature in Dhaka, 
Bangladesh. Remote Sensing, 5(11), 5969-5998. https://doi. org/10.3390/rs5115969.

Arab-rahmatipour, M., Ebadollahi-natanzi, A., \& ArabRahmatipour, G. (2020). Prevention of depression and psychological stress by studying book in quarantine conditions of COVID-19. Sci Medicine Journal, 2(3), 182-183. https://doi.org/10.1002/jmv.25840.

Arias-Reyes, C., Carvajal-Rodriguez, F., Poma-Machicao, L., Aliaga-Raudan, F., Marques, D. A., Zubieta DeUrioste, N., et al. (2020). Decreased incidence, virus transmission capacity, and severity of COVID-19 at altitude on the American continent. medRxiv, 1-18. https://doi.org/10.1101 /2020.07.22.20160168

Auler, A. C., Cássaro, F. A. M., da Silva, V. O., \& Pires, L. F. (2020). Evidence that high temperatures and intermediate relative humidity might favor the spread of COVID-19 in tropical climate: a case study for the most affected Brazilian cities. Science of the Total Environment, 729, 1-34. https://doi.org/10.1016/j.scitotenv.2020.139090.

Babak, O., \& Deutsch, C. V. (2009). Statistical approach to inverse distance interpolation. Stochastic Environmental Research and Risk Assessment, 23(5), 543-553. https://doi. org/10.1007/s00477-008-0226-6.

Bangladesh - Urban population. (2020). knoema. https://doi. org/10.1787/227f2b95-en

Bangladesh Covid-19 update (2020). (2020). Institute of Epidemiology, Disease Control and Research (IEDCR). h t t p s : / / w w w. i e d c r. g o v. b d/ i n d e x . php/component/content/article/73-ncov-2019

Bashir, M. F., Ma, B., Bilal, Komal, B., Bashir, M. A., Tan, D., \& Bashir, M. (2020). Correlation between climate indicators and COVID-19 pandemic in New York, USA. Science of the Total Environment, 728, 1-4. https://doi.org/10.1016/j. scitotenv.2020.138835

Begum, B. A., Hopke, P. K., \& Markwitz, A. (2013). Air pollution by fine particulate matter in Bangladesh. Atmospheric Pollution Research, 4(1), 75-86. https://doi.org/10.5094 /APR.2013.008.

Benaissa, F., \& Alkama, R. (2019). Bioindication of urban air polycyclic aromatic hydrocarbons using petunia hybrida. Civil Engineering Journal, 5(6), 1305-1313. https://doi. org/10.28991/cej-2019-03091333.

BMD. (2020). Bangladesh Meteorological Department. http://live3.bmd.gov.bd/. Accessed 14 November 2020.

Bontempi, E. (2020a). First data analysis about possible COVID19 virus airborne diffusion due to air particulate matter (PM): the case of Lombardy (Italy). Environmental Research, 186, 20. https://doi.org/10.1016/j.envres.2020.109639.

Bontempi, E. (2020b). First data analysis about possible COVID19 virus airborne diffusion due to air particulate matter (PM): the case of Lombardy (Italy). Environmental Research, 109639, 109639. https://doi.org/10.1016/j. envres.2020.109639.

Brunsdon, C., Fotheringham, A. S., \& Charlton, M. E. (1996). Geographically weighted regression: a method for exploring spatial nonstationarity. Geographical Analysis, 28(4), 281298. https://doi.org/10.1111/j.1538-4632.1996.tb00936.x.

Casanova, L. M., Jeon, S., Rutala, W. A., Weber, D. J., \& Sobsey, M. D. (2010). Effects of air temperature and relative humidity on coronavirus survival on surfaces. Applied and
Environmental Microbiology, 76(9), 2712-2717. https://doi. org/10.1128/AEM.02291-09.

Ceccato, P., Ramirez, B., Manyangadze, T., Gwakisa, P., \& Thomson, M. C. (2018). Data and tools to integrate climate and environmental information into public health. Infectious Diseases of Poverty, 7(1), 1-11. https://doi.org/10.1186 /s40249-018-0501-9.

Charlton, M., \& Fotheringham, A. S. (2014). Geographically weighted regression. In Handbook of Regional Science (pp. 1-25). https://doi.org/10.1007/978-3-642-23430-9 77.

Chen, F. W., \& Liu, C. W. (2012). Estimation of the spatial rainfall distribution using inverse distance weighting (IDW) in the middle of Taiwan. Paddy and Water Environment, 10(3), 209-222. https://doi.org/10.1007/s10333-012-0319-1.

Conticini, E., Frediani, B., \& Caro, D. (2020). Can atmospheric pollution be considered a co-factor in extremely high level of SARS-CoV-2 lethality in Northern Italy? Environmental Pollution, 261, 1-3. https://doi.org/10.1016/j. envpol.2020.114465.

Desai, D. (2020). Urban densities and the Covid-19 pandemic: upending the sustainability myth of global megacities (No. 244). Observer Research Foundation. https://www. orfonline.org/research/urban-densities-and-the-covid-19pandemic-upending-the-sustainability-myth-ofglobalmegacities-65606/.

Domingo, J. L., \& Rovira, J. (2020). Effects of air pollutants on the transmission and severity of respiratory viral infections. Environmental Research, 187, 1-7. https://doi.org/10.1016 /j.envres.2020.109650.

Engel-Cox, J. A., Holloman, C. H., Coutant, B. W., \& Hoff, R. M. (2004). Qualitative and quantitative evaluation of MODIS satellite sensor data for regional and urban scale air quality. Atmospheric Environment, 38(16), 2495-2509. https://doi. org/10.1016/j.atmosenv.2004.01.039.

ESRI. (2020). How IWD works. https://desktop.arcgis. com/en/arcmap/10.3/tools/3d-analyst-toolbox/how-idwworks.htm. Accessed 10 September 2020.

Fotheringham, A. S., Charlton, M. E., \& Brunsdon, C. (1998). Geographically weighted regression: a natural evolution of the expansion method for spatial data analysis. Environment and Planning A, 30(11), 1905-1927. https://doi.org/10.1068 /a301905.

Franke, R. (1982). Scattered data interpolation: tests of some method. Mathematics of Computation, 38(157), 181. https://doi.org/10.2307/2007474.

Gorbalenya, A., Baker, S., Baric, R., de Groot, R., Drosten, C., Gulyaeva, A., et al. (2020). Severe acute respiratory syndrome-related coronavirus: the species and its viruses a statement of the Coronavirus Study Group. Nature Microbiology, 1-15. https://doi.org/10.1101 /2020.02.07.937862.

Guan, W., Ni, Z., Hu, Y., Liang, W., Ou, C., He, J., Liu, L., Shan, H., Lei, C. L., Hui, D. S. C., du, B., Li, L. J., Zeng, G., Yuen, K. Y., Chen, R. C., Tang, C. L., Wang, T., Chen, P. Y., Xiang, J., Li, S. Y., Wang, J. L., Liang, Z. J., Peng, Y. X., Wei, L., Liu, Y., Hu, Y. H., Peng, P., Wang, J. M., Liu, J. Y., Chen, Z., Li, G., Zheng, Z. J., Qiu, S. Q., Luo, J., Ye, C. J., Zhu, S. Y., Zhong, N. S., \& China Medical Treatment Expert Group for Covid-19. (2020). Clinical characteristics of coronavirus disease 2019 in China. New England Journal of 
Medicine, 382(18), 1-13. https://doi.org/10.1056 Inejmoa2002032.

Guttikunda, S. K., Begum, B. A., \& Wadud, Z. (2013). Particulate pollution from brick kiln clusters in the greater Dhaka region, Bangladesh. Air Quality, Atmosphere and Health, 6(2), 357365. https://doi.org/10.1007/s11869-012-0187-2.

Harlem, G., \& Lynn, M. (2020). Descriptive analysis of social determinant factors in urban communities affected by COVID-19. Journal of Public Health (Oxford, England), 42(3), 1-4. https://doi.org/10.1093/pubmed/fdaa078.

Hassan, M. M., Juhász, L., \& Southworth, J. (2019). Mapping time-space brickfield development dynamics in peri-urban area of Dhaka, Bangladesh Mohammad. International Journal of Geo-Information, 8(10), 1-27. https://doi. org/10.3390/ijgi8100447.

He, M. Z., Kinney, P. L., Li, T., Chen, C., Sun, Q., Ban, J., Wang, J., Liu, S., Goldsmith, J., \& Kioumourtzoglou, M. A. (2020). Short- and intermediate-term exposure to NO2 and mortality: a multi-county analysis in China. Environmental Pollution, 261(2), 114165 . https://doi.org/10.1016/j. envpol.2020.114165.

Hoque, M. A., Hoque, M. M., \& Ahmed, K. M. (2007). Declining groundwater level and aquifer dewatering in Dhaka metropolitan area, Bangladesh: causes and quantification. Hydrogeology Journal, 15(8), 1523-1534. https://doi. org/10.1007/s10040-007-0226-5.

Hu, H., Nigmatulina, K., \& Eckhoff, P. (2013). The scaling of contact rates with population density for the infectious disease models. Mathematical Biosciences, 244(2), 125-134. https://doi.org/10.1016/j.mbs.2013.04.013.

Huang, C., Wang, Y., Li, X., Ren, L., Zhao, J., Hu, Y., Zhang, L., Fan, G., Xu, J., Gu, X., Cheng, Z., Yu, T., Xia, J., Wei, Y., Wu, W., Xie, X., Yin, W., Li, H., Liu, M., Xiao, Y., Gao, H., Guo, L., Xie, J., Wang, G., Jiang, R., Gao, Z., Jin, Q., Wang, J., \& Cao, B. (2020). Clinical features of patients infected with 2019 novel coronavirus in Wuhan, China. The Lancet, 395(10223), 1-10. https://doi.org/10.1016/S0140-6736(20 )30183-5.

Islam, N., Shabnam, S., \& Erzurumluoglu, A. M. (2020). Temperature, humidity, and wind speed are associated with lower Covid-19 incidence. medRxiv, 1-4. https://doi. org/10.1101/2020.03.27.20045658.

Leung, Y., Mei, C. L., \& Zhang, W. X. (2000). Statistical tests for spatial nonstationarity based on the geographically weighted regression model. Environment and Planning A, 32(1), 9-32. https://doi.org/10.1068/a3162.

Li, H., Xu, X., Dai, D., Huang, Z., Ma, Z., \& Guan, Y. (2020a). International Journal of Infectious Diseases Air pollution and temperature are associated with increased COVID-19 incidence : a time series study. International Journal of Infectious Diseases, 97, 278-282. https://doi.org/10.1016/j. ijid.2020.05.076.

Li, W., Thomas, R., El, H., Piechota, T., Struppa, D., \& Ghaffar, K. A. A. (2020b). Investigating the significance of aerosols in determining the coronavirus fatality rate among three European countries. Earth Systems and Environment, 4(3), 513-522. https://doi.org/10.1007/s41748-020-00176-4.

Luo, W., Majumder, M. S., Liu, D., Poirier, C., Mandl, K. D., Lipsitch, M., \& Santillana, M. (2020). The role of absolute humidity on transmission rates of the COVID-19 outbreak. medRxiv, 7. https://doi.org/10.1101/2020.02.12.20022467.
Ma, Y., Zhao, Y., Liu, J., He, X., Wang, B., Fu, S., Yan, J., Niu, J., Zhou, J., \& Luo, B. (2020). Effects of temperature variation and humidity on the death of COVID-19 in Wuhan, China. Science of the Total Environment, 724, 138226. https://doi. org/10.1016/j.scitotenv.2020.138226.

Manisalidis, I., Stavropoulou, E., Stavropoulos, A., \& Bezirtzoglou, E. (2020). Environmental and health impacts of air pollution: a review. Frontiers in Public Health, 8, 1-13. https://doi.org/10.3389/fpubh.2020.00014.

Martelletti, L., \& Martelletti, P. (2020). Air pollution and the novel Covid-19 disease: a putative disease risk factor. $S N$ Comprehensive Clinical Medicine, 2(4), 383-387. https://doi.org/10.1007/s42399-020-00274-4.

Mukherji, N. (2020). The social and economic factors underlying the incidence of COVID-19 cases and deaths in US counties. medRxiv, 1-19. https://doi.org/10.1101 /2020.05.04.20091041.

Mulenga, D., \& Siziya, S. (2019). Indoor air pollution related respiratory ill health, a sequel of biomass use. Sci Med J, 1(1), 30-37. https://doi.org/10.28991/SciMedJ-2019-01015.

Nakada, L. Y. K., \& Urban, R. C. (2020). COVID-19 pandemic: environmental and social factors influencing the spread of SARS-CoV-2 in São Paulo, Brazil. Environmental Science and Pollution Research. https://doi.org/10.1007/s11356020-10930-w.

Ogen, Y. (2020). Assessing nitrogen dioxide (NO2) levels as a contributing factor to coronavirus (COVID-19) fatality. Science of the Total Environment, 726, 1-5. https://doi. org/10.1016/j.scitotenv.2020.138605.

Ortiz, C., Linares, C., Carmona, R., \& Díaz, J. (2017). Evaluation of short-term mortality attributable to particulate matter pollution in Spain. Environmental Pollution, 224, 541-551. https://doi.org/10.1016/j.envpol.2017.02.037.

Pansini, R., \& Fornacca, D. (2020). Early evidence of a higher incidence of COVID-19 in the air- polluted regions of eight severely affected countries corresponding authors digital supplement early evidence of a higher incidence of COVID-19 in the air- polluted regions of eight severely aff. medRxiv, 117. https://doi.org/10.1101/2020.04.30.20086496.

Pavel, M. R. S., Salam, A., Yesmin, M., Ahsan, N., Zaman, S. U., \& Jeba, F. (2020). Impact and correlation of air quality and climate variables with COVID-19 morbidity and mortality in Dhaka, Bangladesh. medRxiv, 1-28. https://doi.org/10.1101 /2020.09.12.20193086.

Pedrosa, R. H. L. (2020). The dynamics of Covid-19: weather, demographics and infection timeline. medRxiv, 1-17. https://doi.org/10.1101/2020.04.21.20074450.

Qi, H., Xiao, S., Shi, R., Ward, M. P., Chen, Y., Tu, W., Su, Q., Wang, W., Wang, X., \& Zhang, Z. (2020). COVID-19 transmission in Mainland China is associated with temperature and humidity: a time-series analysis. Science of the Total Environment., 728, 138778. https://doi.org/10.1016/j. scitotenv.2020.138778.

Rendana, M. (2020). Impact of the wind conditions on COVID-19 pandemic: a new insight for direction of the spread of the virus. Urban Climate, 34, 1-8. https://doi.org/10.1016/j. uclim.2020.100680.

Rocklöv, J., \& Sjödin, H. (2020). High population densities catalyse the spread of COVID-19. Journal of Travel Medicine, 27(3), 1-2. https://doi.org/10.1093/jtm/taaa038. 
Saha, C. K., \& Hosain, J. (2016). Impact of brick kilning industry in peri-urban Bangladesh. International Journal of Environmental Studies, 73(4), 491-501. https://doi. org/10.1080/00207233.2016.1179014.

Șahin, M. (2020). Impact of weather on COVID-19 pandemic in Turkey. Science of the Total Environment, 728, 138810. https://doi.org/10.1016/j.scitotenv.2020.138810.

Sajadi, M. M., Habibzadeh, P., Vintzileos, A., Miralles-wilhelm, F., \& Amoroso, A. (1992). Temperature, humidity, and latitude analysis to predict potential spread and seasonality for COVID-19. Ssrn, 410, e2011834. https://doi.org/10.1001 /jamanetworkopen.2020.11834.

Sharma, S., Zhang, M., Anshika, Gao, J., Zhang, H., \& Kota, S. H. (2020). Effect of restricted emissions during COVID-19 on air quality in India. Science of the Total Environment, 728, 18. https://doi.org/10.1016/j.scitotenv.2020.138878.

Shepard, D. (1968). Two- dimensional interpolation function for irregularly- spaced data. Proc 23rd Nat Conf, 517-524. https://doi.org/10.1145/800186.810616.

Skinder, B. M., Pandit, A. K., Sheikh, A. Q., \& Ganai, B. A. (2014). Brick kilns: cause of atmospheric pollution. Journal of Pollution Effects \& Control, 02(02), 1-7. https://doi. org/10.4172/2375-4397.1000112.

Tusher, T. R., Ashraf, Z., \& Akter, S. (2019). Health effects of brick kiln operations: a study on largest brick kiln cluster in Bangladesh. South East Asia Journal of Public Health, 8(1), 32-36. https://doi.org/10.3329/seajph.v8i1.42270.

University, H. (2020). COVID-19 dashboard by the Center for Systems Science and Engineering (CSSE) at Johns Hopkins University (JHU). https://coronavirus.jhu.edu/map.html. Accessed 3 December 2020.

Wang, J., Tang, K., Feng, K., Lin, X., Lv, W., Chen, K., \& Wang, F. (2020). High temperature and high humidity reduce the transmission of COVID-19. SSRN, 1-33. https://doi. org $/ 10.2139 /$ ssrn.3551767.

Wheeler, D. C., \& Páez, A. (2010). Handbook of applied spatial analysis., 461-486. https://doi.org/10.1007/978-3-64203647-7 22.

WHO. (2020). COVID-19 situation report No. 10. WHO. Dhaka. h t t p s : / / w w w . w ho. in t/docs/defa u $1 \mathrm{t}$ source/searo/bangladesh/covid-19-who-bangladeshsituationreports/who-ban-covid-19-sitrep-10.pdf?sfvrsn=c0aac0 b8_4.

Worldometers. (2017). Bangladesh population. Online. h t t p s: / / w w w . worldometers.info/world population/bangladesh-population/. Accessed 3 Dec 2020.
Wu, X., Nethery, R., Sabath, B., Braun, D., \& Dominici, F. (2020a). Exposure to air pollution and COVID-19 mortality in the United States: a nationwide cross-sectional study. medRxiv : the preprint server for health sciences, 1-36. https://doi.org/10.1101/2020.04.05.20054502.

Wu, Y., Jing, W., Liu, J., Ma, Q., Yuan, J., Wang, Y., du, M., \& Liu, M. (2020b). Effects of temperature and humidity on the daily new cases and new deaths of COVID-19 in 166 countries. Science of the Total Environment, 729, 139051. https://doi.org/10.1016/j.scitotenv.2020.139051.

Xie, J., \& Zhu, Y. (2020a). Association between ambient temperature and COVID-19 infection in 122 cities from China. Science of the Total Environment, 724, 138201. https://doi. org/10.1016/j.scitotenv.2020.138201.

Xie, J., \& Zhu, Y. (2020b). Association between ambient temperature and COVID-19 infection in 122 cities from China. Science of the Total Environment, 724, 1-5. https://doi. org/10.1016/j.scitotenv.2020.138201.

Xu, R., Rahmandad, H., Gupta, M., DiGennaro, C., Ghaffarzadegan, N., Amini, H., \& Jalali, M. (2020). The modest impact of weather and air pollution on COVID-19 transmission. SSRN Electronic Journal, 3, 1-46. https://doi. org/10.1101/2020.05.05.20092627.

Yao, Y., Pan, J., Wang, W., Liu, Z., Kan, H., Qiu, Y., Meng, X., \& Wang, W. (2020). Association ofparticulate matter pollution and case fatality rate of COVID-19 in 49 Chinese cities. Science of the Total Environment, 741, 1-25. https://doi. org/10.1016/j.scitotenv.2020.140396.

You, H., Wu, X., \& Guo, X. (2020). Distribution of covid-19 morbidity rate in association with social and economic factors in Wuhan, China: implications for urban development. International Journal of Environmental Research and Public Health, 17(10), 1-14. https://doi.org/10.3390 /ijerph17103417.

Zhou, J., Qin, L., Meng, X., \& Liu, N. (2020). The interactive effects of ambient air pollutants-meteorological factors on confirmed cases of COVID-19 in 120 Chinese cities. medRxiv, 1-26. https://doi.org/10.1101 /2020.05.27.20111542.

Publisher's note Springer Nature remains neutral with regard to jurisdictional claims in published maps and institutional affiliations. 